BNL-NCS-63380-00/05-REV .

\title{
EXFOR Basics \\ A Short Guide to the \\ Neutron Reaction Data Exchange Format
}

\author{
Victoria McLane \\ National Nuclear Data Center \\ on behalf of the \\ Nuclear Data Center Network
}

May 2000

Brookhaven National Laboratory
Upton, NY 11973-5000 



\section{Table of Contents}

INTRODUCTION

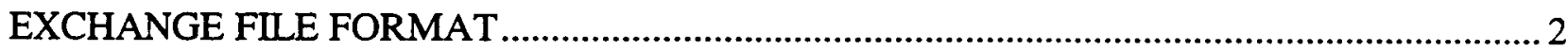

Permitted character set ........................................................................................... 3

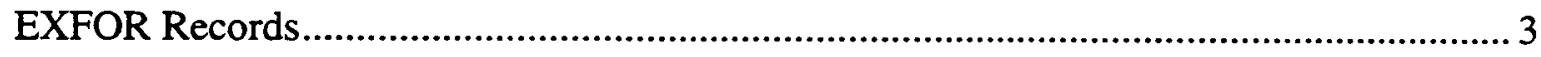

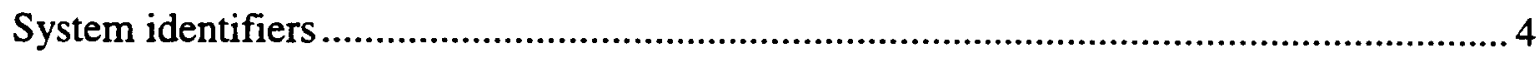

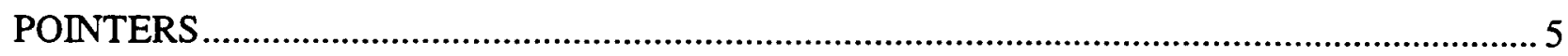

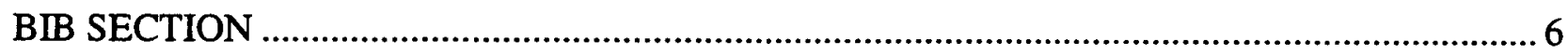

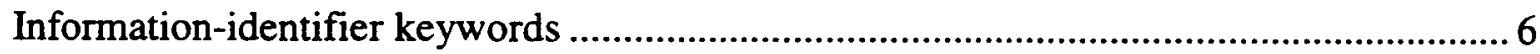

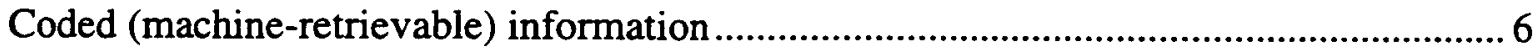

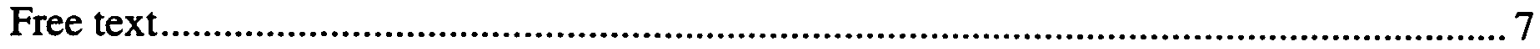

Coding of nuclides and compounds ............................................................................

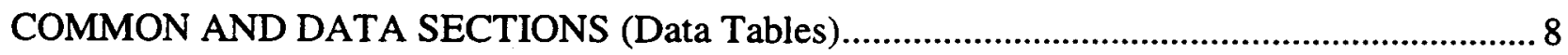

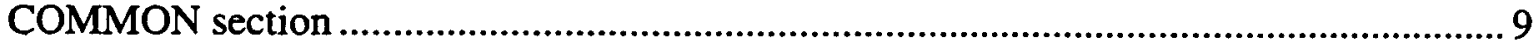

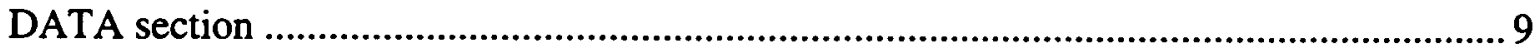

APPENDIX A. Nuclear Reaction Data Centers

APPENDIX B. Information-Identifier Keywords

APPENDIX C. List of Dictionaries

APPENDDX D. Covariance Data File Format

APPENDIX E. Example of an EXFOR Entry 


\section{Acknowlegements}

This work was performed under the auspices of the U. S. Department of Energy, Division of Nuclear Physics, Office of Science.

The author would like to thank the members of the Nuclear Data Center Network, especially, H. D. Lemmel and O. Schwerer of the International Atomic Energy Agency Nuclear Data Section, and S. Maev of the Russian Nuclear Data Center for their contributions. 


\section{INTRODUCTION}

This manual is intended as a guide to users of nuclear reaction data compiled in the EXFOR format, and is not intended as a complete guide to the EXFOR System. ${ }^{1}$

EXFOR is the exchange format designed to allow transmission of nuclear reaction data between the Nuclear Reaction Data Centers. ${ }^{2}$ In addition to storing the data and its' bibliographic information, experimental information is also compiled. The status (e.g., the source of the data) and history (e.g., date of last update) of the data set is also included.

EXFOR is designed for flexibility in order to meet the diverse needs of the nuclear reaction data centers. It was originally conceived for the exchange of neutron data and was developed through discussions among personnel from centers situated in Saclay, Vienna, Livermore and Brookhaven. It was accepted as the official exchange format of the neutron data centers at Saclay, Vienna, Brookhaven and Obninsk, at a meeting held in November 1969. ${ }^{3}$ As a result of two meetings held in 1975 and $1976^{4}$ and attended by several charged-particle data centers, the format was further developed and adapted to cover all nuclear reaction data.

The exchange format should not be confused with a center-to-user format. Although users may obtain data from the centers in the EXFOR format, other center-to-user formats have been developed to meet the needs of the users within each center's own sphere of responsibility.

The EXFOR format, as outlined, allows a large variety of numerical data tables with explanatory and bibliographic information to be transmitted in a format:

- that is machine-readable (for checking and indicating possible errors);

- that can be read by personnel (for passing judgement on and correcting errors).

The data presently included in the EXFOR exchange file include:

- a "complete" compilation of experimental neutron-induced reaction data,

- a selected compilation of charged-particle-induced reaction data,

- a selected compilation of photon-induced reaction data.

1 For a complete guide to the EXFOR System, see EXFOR Systems Manual, Brookhaven National Laboratory report BNL-NCS-63330 (1999).

2 See Appendix A for a list of the Nuclear Reaction Data Centers and their areas of responsibilities.

3 See IAEA report INDC(NDS)-16/N (December 1969).

4 See IAEA report INDC(NDS)-69 (December 1975) and INDC(NDS)-77 (October 1976). 


\section{EXCHANGE FILE FORMAT}

An exchange file contains a number of entries (works). Each entry is divided into a number of subentries (data sets). Each entry is assigned an accession number; each subentry is assigned a subaccession number (the accession number plus a subentry number). The subaccession numbers are associated with a data table throughout the life of the EXFOR system.

The subentries are further divided into:

- bibliographic, descriptive and bookkeeping information (hereafter called BIB information),

- common data that applies to all data throughout the subentry, and

- a data table.

The file may, therefore, be considered to be of the following form:

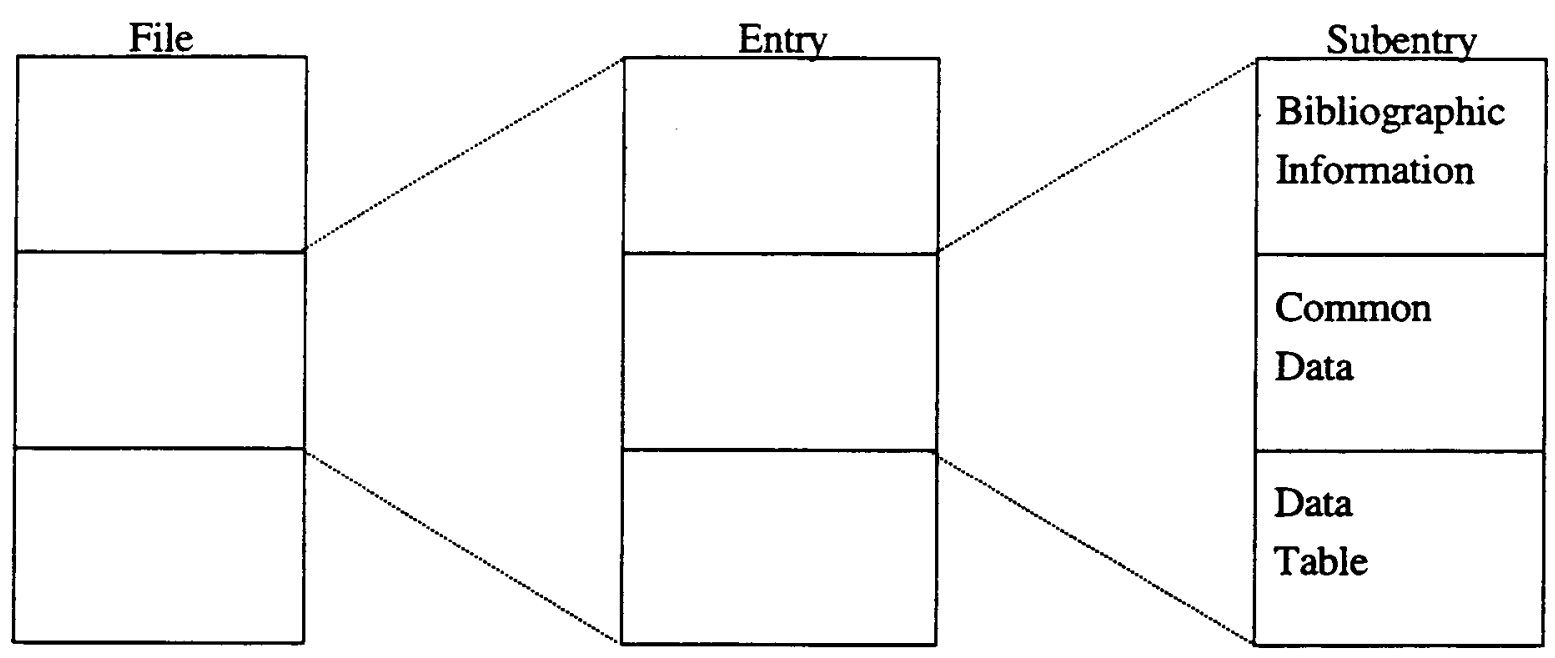

In order to avoid repetition of information that is common to all subentries within an entry or to all lines within a subentry, information may be associated with an entire entry or with an entire subentry. To accomplish this, the first subentry of each work contains only information that applies to all other subentries. Within each subentry, the information common to all lines of the table precedes the table. Two levels of hierarchy are thereby established:

\begin{tabular}{|c|c|}
\hline Entry & Subentries \\
\hline \multirow{2}{*}{$\begin{array}{l}\text { Common } \\
\text { Subentry }\end{array}$} & $\begin{array}{l}\text { Bibliographic } \\
\text { Information }\end{array}$ \\
\hline & Common Data \\
\hline \multirow{3}{*}{$\begin{array}{l}\text { Data } \\
\text { Subentry }\end{array}$} & $\begin{array}{l}\text { Bibliographic } \\
\text { Information }\end{array}$ \\
\hline & Common Data \\
\hline & Data Table \\
\hline
\end{tabular}


Permitted Character Set. The following characters are permitted for use in the exchange format:

All Roman characters, $A$ to $Z$ and a to $\mathrm{Z}$

All numbers, 0 to 9

The special characters:
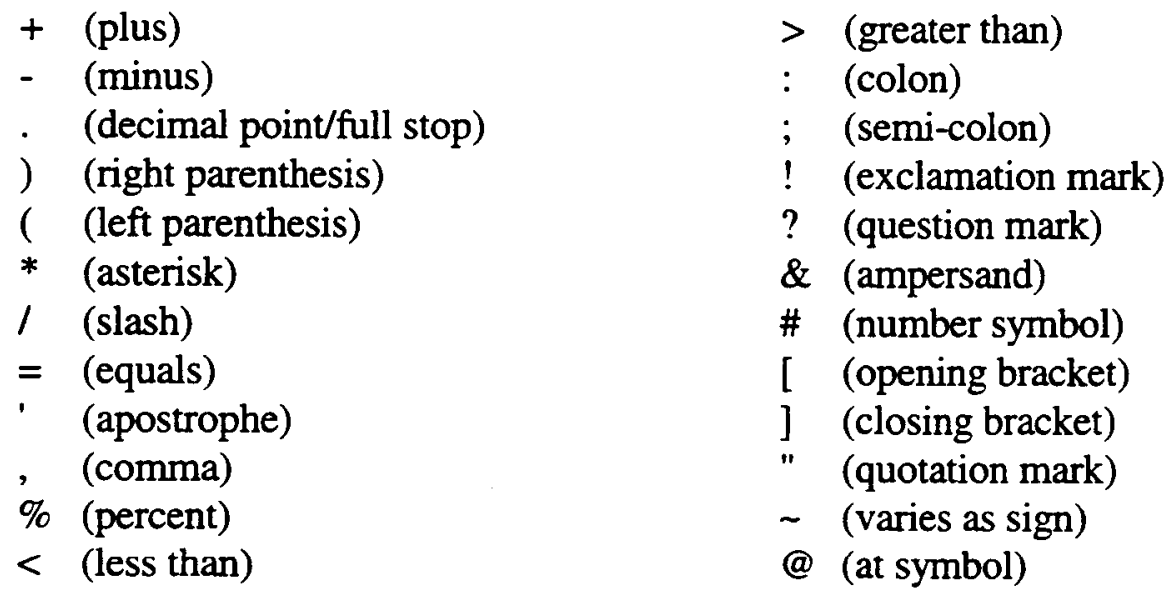

\section{EXFOR Records}

EXFOR Exchange files consist of 80 character ASCII records. The format of columns 1-66 varies according to the record type as outlined in the following chapters. Columns 67-79 is used to uniquely identify a record within the file. The records on the file are in ascending order according to the record identification. Column 80 is reserved for an alteration flag.

Record identification. The record identification is divided into three fields: the accession number (entry), subaccession number (subentry), and record number within the subentry. The format of these fields is as follows.
Columns 67-71 Center-assigned accession number
72-74 Subaccession number
75-79 Sequence number

Alteration flag (column 80). The last column of each record contains the alteration flag which is used to indicate that a record and/or following records has been altered (i.e., added, deleted or modified) since the work was last transmitted. The flag field will normally contain a blank to indicate an unaltered record. 


\section{System Identifiers}

Each of the sections of an EXFOR file begins and ends with a system identifier. Each of the following system identifiers indicates the beginning of one of these sections.

$\begin{array}{ll}\text { TRANS } & \text { - A file is the unit } \\ \text { ENTRY } & \text { - An entry is the unit } \\ \text { SUBENT } & \text { - A subentry is the unit } \\ \text { BIB } & \text { - A BIB Information section is the unit } \\ \text { COMMON } & \text { - A common data section is the unit } \\ \text { DATA } & \text { - A data table section is the unit }\end{array}$

- The end of unit is signaled by modifier END preceding the basic system identifier, e.g., NODATA.

- A positive indication that a unit is intentionally omitted is signaled by the modifier NO preceding the basic system identifier, e.g., NOSUBENT.

The following system identifiers are defined.

1. A file is:

Headed by: TRANS cxxx , yyyymmdd $C X X X=$ the center-identification character, ${ }^{5}$ yyyymmdd = date (year, month, and day) on which the file was generated.

Ended by: $\quad$ ENDTRANS N1 $\mathrm{N} 1=$ number of entries (accession numbers) on the file.

2. An entry is:

Headed by: N1 NTRY N2 $\mathrm{Nl}=5$-character accession number $\mathrm{N} 2$ = Date of last update (or date of entry if never updated) (yyyymmdd)

Ended by: $\quad$ ENDENTRY N1 N1 - The number of subentries in the work. ${ }^{6}$

N2 - Presently unused (may be blank or zero).

3. A subentry is:

Headed by: SUBENT N1 N2

N1 = 8-character subaccession number (accession number and subentry number). N2 = Date of last update (or date of entry if never updated) (yyyymmdd).

Ended by: $\quad$ ENDSUBENT N1

N1 - $\quad$ The number of records within the subentry.

If a subentry has been deleted, the following record is included in the file

NOSUBENT N1 N2

$\mathrm{N} 1=8$-character subaccession number.

N2 = Date of last alter.

\footnotetext{
${ }^{5}$ On files that contain entries with different file-identification characters, column 67 is assigned such that the record sorts at the beginning of the file.

${ }^{6}$ NOSUBENT records are counted as subentries when computing the number of subentries in an entry.
} 
4. A BIB section is:

Headed by BIB N1 N2

$\mathrm{N} 1=$ Number of information-identifier keywords in the BIB section.

$\mathrm{N} 2=$ Number of records in the BIB section.

Ended by: $\quad$ ENDBIB N1

N1 - $\quad$ Number of records in BIB section.

If no BIB section is given the following record is included:

NOBIB

5. A COMMON section is:

Headed by: COMMON N1 N2

$\mathrm{N} 1=$ Number of common data fields.

$\mathrm{N} 2$ = Number of records within the common section.

Ended by: $\quad$ ENDCOMMONN1

$\mathrm{N} 1 \mathrm{=}$ Number of records within the common section.

If no COMMON section is given, the following record is included: NOCOMMON

6. A DATA section is:

Headed by: NATA N1

$\mathrm{N} 1=$ Number of fields (variables) associated with each line of a data table.

N2 = Number of data lines within the table (excluding headings and units).

Ended by: $\quad$ ENDDATA N1

N1 - $\quad$ Number of records within the data section.

If no DATA section is given, the following record is included:

NODATA

\section{POINTERS}

Different pieces of EXFOR information may be linked together by pointers. A pointer is a numeric or alphabetic character $(1,2 \ldots 9, \mathrm{~A}, \mathrm{~B}, \ldots \mathrm{Z})$ placed in the eleventh column of the information-identifier keyword field in the BIB section and in the field headings in the COMMON or DATA section.

Pointers may link, for example,

- one of several reactions with its data field;

- one of several reactions with a specific piece of information in the BIB section (e.g., ANALYSIS), and/or with a value in the COMMON section, and/or with a field in the DATA section;

- a value in the COMMON section with any field in the DATA section.

In general, a pointer is valid for only one subentry. A pointer used in the first subentry applies to all subentries and has a unique meaning throughout the entire entry. 


\section{BIB SECTION}

The BIB section contains the bibliographic information (e.g., reference, authors), descriptive information (e.g., neutron source, method, facility), and administrative information (e.g., history) associated with the data presented. It is identified on an exchange file as that information between the system identifiers BIB and ENDBIB.

A BIB record consists of three parts:

columns 1-11: information-identifier keyword field,

columns 12-66: information field, which may contain coded information and/or free text, columns 67-80: record identification and alteration flag fields.

$\mathrm{BIB}$ information for a given data set consists of the information contained in the BIB section of its subentry together with the $\mathrm{BIB}$ information in subentry 001 . That is, information coded in subentry 001 applies to all other subentries in the same entry. A specific information-identifier keyword may be included in either subentry or both.

\section{Information-identifier keywords}

The information-identifier keyword is used to define the significance of the information given in columns 12-66. The keyword is left adjusted to begin in column 1 , and does not exceed a length of 10 characters (column 11 is either blank, or contains a pointer, see Chapter 5).

These keywords may, in general, appear in any order within the BIB section, however, an information-identifier keyword is not repeated within any one BIB section. If pointers are present, they appear on the first record of the information to which they are attached and are not repeated on continuation records. A pointer is assumed to refer to all BIB information until either another pointer or a new keyword is encountered. As this implies, pointer-independent information for each keyword appears first.

\section{Coded (machine-retrievable) information}

Coded information may be used:

- to define the actual BIB information,

- as a link to the COMMON and DATA section,

- to enter associated numerical data.

Coded information is enclosed in parentheses and left adjusted so that the opening parenthesis appears in column 12. Several pieces of coded information may be associated with a given information-identifier keyword.

Codes for ùse with a specific keỹuord are found in the relevant dictionarary. Howeverer, for some keywords, the code string may include retrievable information other than a code from one of the dictionaries. 
In general, codes given in the dictionaries may be used singly or in conjunction with one or more codes from the same dictionary. Two options exist if more than one code is used:

a) two or more codes within the same set of parenthesis, separated by a comma;

Example: (SOLST,NAICR)

b) each code on a separate record, enclosed in it's own set of parenthesis starting in column 12 , followed by free text.

Example: (SOLST) free text

(NAICR) free text

For some cases, the information may be continued onto successive records. Information on continuation records does not begin before column 12 (columns 1-10 are blank and column 11 is blank or contains a pointer).

Note that some information-identifier keywords have no coded information associated with them and that, for many keywords which may have coded information associated with them, it need not always be present.

\section{Eree text}

Free text may be entered in columns 12-66 under each of the information-identifier keywords in the BIB section. The text follows any coded information on the record or may begin on a separate record; it may be continued onto any number of records.

The language of the free text is English.

\section{Coding of nuclides and compounds.}

Nuclides appear in the coding of many keywords. The general code format is $Z-S-A-X$, where:

$Z$ is the charge number; up to 3 digits, no leading zeros

$S$ is the element symbol; 1 or 2 characters (Dictionary 8 )

$A$ is the mass number; up to 3 digits, no leading zeroes. A single zero denotes natural isotopic composition.

$X$ is an isomer code denoting the isomeric state; this subfield is not used if there are no known isomeric states.

$X$ may have the following values:

G for ground state (of a nucleus which has a metastable state)

$M \quad$ if only one metastable state is regarded

M1 for the first metastable state

M2 for the second, etc.

T for sum of all isomers (limited to use within an isomeric ratio in SF4 of the reaction string)

\section{Examples: 92-U-235}

$49-I N-115-M / T$

Compounds may in some cases replace the nuclide code. The general format for coding compounds is either the specific compound code, taken from Dictionary 9, or the general code for a compound of the form Z-S-CMP.

Example: 26-FE-CMP 


\section{COMMON AND DATA SECTIONS}

A data table is, generally, a function of one or more independent variables, e.g.,

- $X$ vs. $Y$, e.g., energy, cross section

- $X, X^{\prime}$ and $Y$, e.g., energy and angle; differential cross section

- $X, X^{\prime}$ and $X^{\prime \prime}$ vs. $Y$, e.g., energy, secondary energy, angle, partial angular distribution.

When more than one representation of $Y$ is present, the table may be $X$ vs. $Y$ and $Y^{\prime}$, with associated errors for $X, Y$ and $Y^{\prime}\left(e . g ., X=\right.$ energy, $Y=$ absolute cross section, $Y^{\prime}=$ relative cross section), and possible associated information. The criteria for grouping $Y$ with $Y^{\prime}$ are that they both be derived from the same experimental information by the author of the data.

For some data, the data table does not have an independent variable $X$ but only a function $Y$. (Examples: Spontaneous $\bar{v}$; resonance energies without resonance parameters)

Additional variables may be associated with the data, e.g., errors, standards.

The format of the common data (COMMON) and data table (DATA) sections is identical. Each section is a table of data containing the data headings and units associated with each field. The difference between the common data and data table is:

- The common data contains constant parameters that apply to each line of a point data table;

- The data table contains fields of information; each field, generally, contains values as a function of one or more independent variables (e.g., angle, angular error, cross section, cross section error), i.e., one or more lines of data.

Each physical record may contain up to six information fields, each 11 columns wide. If more than six fields are used, the remaining information is contained on the following records. Therefore, a data line consists of up to three physical records. The number of fields in a data line is restricted to 18.

Records are not packed; rather, individual point information is kept on individual records; i.e., if only four fields are associated with a data line, the remaining two fields are left blank, and, in the case of the data table, the information for the next line begins on the following record. These rules also apply to the headings and units associated with each field.

The content of the COMMON and DATA sections are as follows:

- Eield headings: a data heading left adjusted to the beginning of each field (columns 1, 12, 23, 34, $45,56)$, plus, perhaps, a pointer placed in the last $\left(11^{\text {th }}\right)$ column of a field.

- Data units: left adjusted to the beginning of each field (columns 1, 12, 23, 34, 45, 56).

- Numerical data: FORTRAN-readable using a floating-point format, as follows.

- A decimal point is always present, even for integers.

- A decimal number without an exponent can have any position within the 11-character field.

- No blank is allowed following a sign (+ or -).

- A plus sign may be omitted, except that of an exponent when there is no $\mathrm{E}$. 
- In an exponential notation, the exponent is right adjusted within the 11-character field. The mantissa may have any position.

The values are either zero or have absolute values between $1.0000 \mathrm{E}-38$ and $9.999 \mathrm{E}+38$.

\section{COMMONSection}

The COMMON section is identified as that information between the system identifiers COMMON and ENDCOMMON. In the common data table, only one value is entered for a given field, and successive fields are not integrally associated with one another.

An example of a common data table with more than 6 fields:

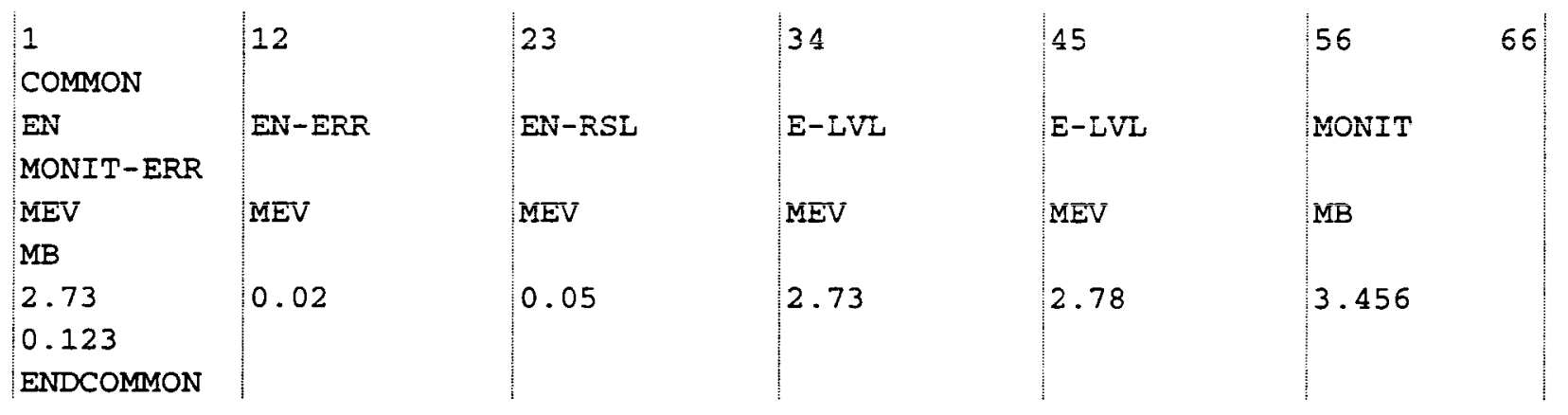

\section{DATASection}

The DATA section is identified as that information between the system identifiers DATA and ENDDATA. In the DATA table, all entries on a record are integrally associated with an individual point. Independent variables precede dependent variables, and are monotonic until the value of the preceding independent variable, if any exist, changes.

Every line in a data table gives data information. This means, for example, that a blank in a field headed DATA is permitted only when another field contains the data information on the same line, e.g., under DATA-MAX. In the same way, each independent variable occurs at least once in each line (e.g., either under data headings E-LVL or E-LVL-MN, E-LVL-MAX, see example following). Supplementary information, such as resolution or standard values, is not given on a line of a data table unless the line includes data information. Blanks are permitted in all fields.

An example of a point data table is shown below with its associated DATA and ENDDATA records.

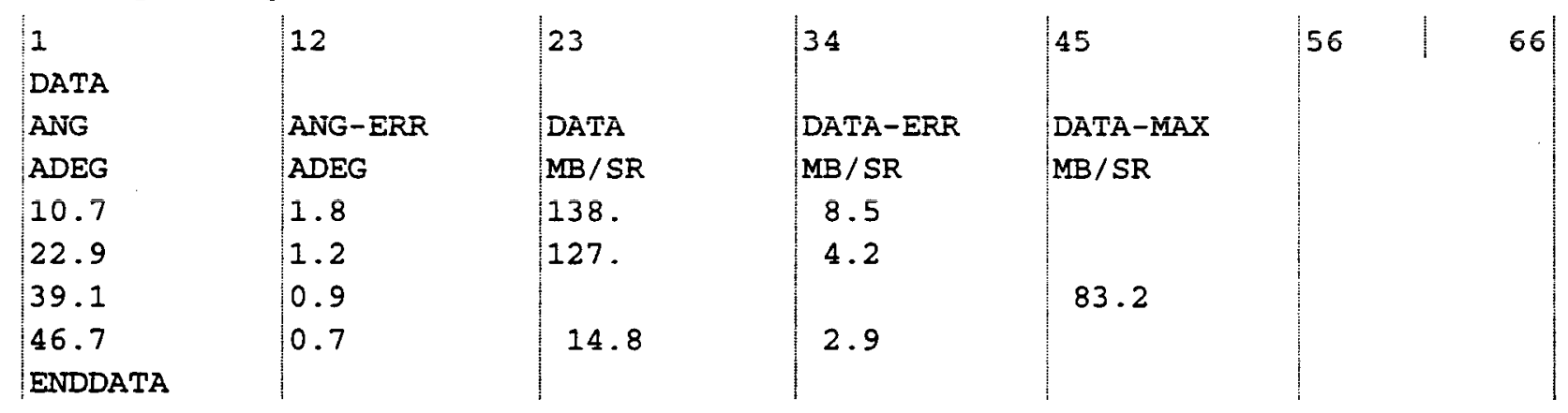


EXFOR Basics 


\section{Appendix A}

\section{Nuclear Reaction Data Centers}

This appendix contains a list of the members of the Nuclear Data Center Network, along with information on how to contact them. Also list are the entry series for which each of the data centers is responsible. 
EXFOR Basics

A. 2 
Principal Centers and their services areas. ${ }^{1}$

\begin{tabular}{|c|c|}
\hline \multicolumn{2}{|l|}{ United States and Canada } \\
\hline $\begin{array}{l}\text { National Nuclear Data Center, } \\
\text { Bldg. 197D } \\
\text { Brookhaven National Laboratory } \\
\text { Upton, NY, 11973-5000 U.S.A. }\end{array}$ & $\begin{array}{l}\text { Center codes: 1, C, L, P, T } \\
\text { Telephone: +1 631-344-2902 } \\
\text { Fax:+1 631-344-2806 } \\
\text { Email: nndc@bnl.gov } \\
\text { or nndcnn@bnl.gov }{ }^{2} \\
\text { www.nndc.bnl.gov }\end{array}$ \\
\hline \multicolumn{2}{|c|}{ O. E. C. D. Nuclear Energy Agency Member Countries } \\
\hline $\begin{array}{l}\text { NEA Data Bank } \\
\text { 12, boulevard des Iles } \\
\text { 92130 Issy-les-Moulineaux, } \\
\text { FRANCE }\end{array}$ & $\begin{array}{l}\text { Center codes: } 2, \text { O } \\
\text { Telephone: +33 (1) } 45241071 \\
\text { Fax: +33 (1) 4524 } 1110 \\
\text { Email:nea@nea.fr } \\
\text { or name@nea.fr } \\
\text { www.nea.fr }\end{array}$ \\
\hline \multicolumn{2}{|l|}{ Countries of the former Soviet Union } \\
\hline $\begin{array}{l}\text { Federal Research Center IPPE } \\
\text { Centr Yadernykh Dannykh } \\
\text { Ploschad Bondarenko } \\
249020 \text { Obninsk, Kaluga Region, } \\
\text { RUSSIA }\end{array}$ & $\begin{array}{l}\text { Center codes: } 4, \mathrm{Q} \\
\text { Telephone: }+7 \text { 084-399-8982 } \\
\text { Fax: +7 095-883-3112 } \\
\text { Email: name@ cjd.obninsk.ru } \\
\text { mdc.ippe.obninsk.ru }\end{array}$ \\
\hline \multicolumn{2}{|l|}{ Remaining countries } \\
\hline $\begin{array}{l}\text { IAEA Nuclear Data Section } \\
\text { Wagramerstr. 5, P.O.Box } 100 \\
\text { A-1400 Vienna, AUSTRIA }\end{array}$ & $\begin{array}{l}\text { Center codes: } 3, \mathrm{D}, \mathrm{G}, \mathrm{V} . \\
\text { Telephone: +43 (1) } 23601709 \text {. } \\
\text { Fax: +43 (1) } 234564 \\
\text { Email: name@iaeand.iaea.or.at } \\
\text { www-nds.iaea.or.at }\end{array}$ \\
\hline
\end{tabular}

\section{Other participating centers.}

\begin{tabular}{|l|l|}
\hline $\begin{array}{l}\text { National Scientific Research Center } \\
\text { Kurchatov Institute } \\
\text { Russia Nuclear Center } \\
46 \text { Ulitsa Kurchatova } \\
123182 \text { Moscow, RUSSIA }\end{array}$ & $\begin{array}{l}\text { Center codes: A, B } \\
\text { Email: feliks@polyn.kiae.su }\end{array}$ \\
\hline $\begin{array}{l}\text { Institute of Nuclear Physics } \\
\text { Moskovskiy Gos. Universitet }\end{array}$ & \\
$\begin{array}{l}\text { Vorob'evy Gory } \\
119899 \text { Moscow, RUSSIA }\end{array}$ & Eenter code: M \\
\hline
\end{tabular}

\footnotetext{
${ }_{2}^{1}$ The four principal centers are responsible for maintaining customer services for the area given.

${ }^{2} n n=$ first and last initial of person to be contacted, e.g., NNDCCD@BNL.GOV.
} 


\begin{tabular}{|l|l|}
\hline China Nuclear Data Center & Center code: S \\
China Institute of Atomic Energy & Email: cndc@mipsa.ciae.ac.cn \\
P.O. BOX 275 (41) & \\
Beijing 102413, CHINA & \\
\hline Japan Charged Particle Reaction Group & Center code: E, R \\
Dept. of Physics & Email: kato@ nucl.phys.hokaido.ac.jp \\
Hokkaido University & \\
Kita-10 Nisha-8, Kita-ku & \\
Sapporo 060, JAPAN & \\
\hline Dr. F. T. Tárkányi & Contributes data under center code D \\
Cyclotron Application Department & Email: tarkanyi @atomki.hu \\
ATOMKI, Institute of Nuclear Research & \\
Bem Tér 18/c, P. O. Box 51 & \\
H-4001 Debrecen, HUNGARY & \\
\hline Russian Federal Center - VNIIEF & Center code: F \\
Sarov, Nizhni Novgorod Region & Email: dunaeva@expd.vniief.ru \\
607 190 pr. Mira 37, RUSSIA & \\
\hline
\end{tabular}


EXFOR Basics

\section{Appendix B}

\section{Information Identifier Keywords}

This appendix provides a listing of all information-identifier keywords, along with details about their use. The keywords appear in alphabetical order. 
EXFOR Basics 
ADD-RES. Gives information about any additional results obtained in the experiment, but which are not compiled in the data tables. Codes are given in Dictionary 20.

Example: ADD-RES (RANGE) Range of recoils measured.

ANALYSIS. Gives information as to how the experimental results have been analyzed to obtain the values given under the heading DATA which actually represent the results of the analysis. Codes are found in Dictionary 23.

Example: ANLAYSIS (MLA) Breit-Wigner multilevel analysis

ASSUMED Gives information about values assumed in the analysis of the data, and about COMMON or DATA fields headed by ASSUM or its derivatives. The format of the code is: (heading,reaction, quantity)

Heading field: data heading to be defined.

Reaction field and quantity field: coded as under the keyword REACTION.

Example:

ASSUMED (ASSUM, 6-C-12 (N, TOT), , SIG)

AUTHOR. Gives the authors of the work reported.

\section{Example:}

AUTHOR (R.W.MCNally Jr, A.B.JONES)

COMMENT. Gives pertinent information which cannot logically be entered under any other of the keywords available.

CORRECTION. Gives information about corrections applied to the data in order to obtain the values given under DATA. See also LEXFOR, Correction.

COVARIANCE. Gives covariance information provided by the experimentalist, or to flag the existence of a covariance data file. See Appendix $C$ for covariance file format.

Example: COVARIANCE (COVAR) COVARIANCE FILE EXISTS AND MAY BE OBTAINED ON REQUEST.

CRITIQUE. Gives comments on the quality of the data presented in the data table. 
DECAY-DATA. Gives the decay data for any nuclide occurring in the reaction measured as assumed or measured by the author for obtaining the data given ${ }^{1}$. The general format of the coding string consists of three major fields which may be preceded by a decay flag:

((decay flag)nuclide, half-life,radiation).

Flag. A fixed-point number that also appears in the data section under the data heading DECAY-FLAG. If the flag may be omitted, its parentheses are also omitted.

Nuclide field. A nuclide code.

Half-life field. The half-life of the nuclide specified, coded as a floating-point number, followed by a unit code with the dimensions of TIME.

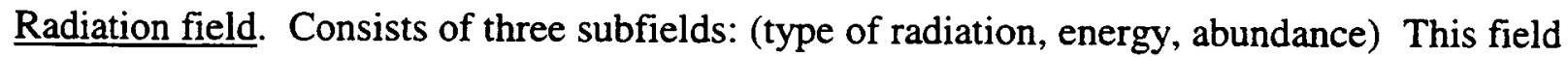
may be omitted, or repeated (each radiation field being separated by a comma). The absence of any subfield is indicated by a comma; trailing commas are not included.

SF1. Type-of-radiation. A code from Dictionary 13. Where two or more different decay modes are possible and are not distinguished in the measurement, two or more codes are given; each separated by a slash. (See Example b, following).

SF2. Energy. The energy of the radiation in $\mathrm{keV}$, coded as a floating-point number. In the case of two or more unresolved decays, two or more energies, or a lower and upper energy limit, are given, each separated by a slash. (See Example e).

SF3. Abundance. The abundance of the observed per decay, coded as a floating-point number.

\section{Examples}

a) DECAY-DATA (60-ND-140,3.3D) (radiation field omitted)

b) DECAY-DATA $(59-P R-140, . B+/ E C, 0.500)$ (half-life and decay energy omitted)

c) DECAY-DATA (25-MN-50-G,0.286SEC, B+,6610.) (abundance omitted)

d) DECAY-DATA $((1) 60-.\mathrm{ND}-138,5.04 \mathrm{HR}, \mathrm{DG}, 328,0.065)$ (decay flag, all fields present)

e) DECAY-DATA $(60-\mathrm{ND}-139-\mathrm{M}, 5.5 \mathrm{HR}, \mathrm{DG}, 708 . / 738,0.64)$ (the abundance given is the total abundance of both $\gamma$ rays)

f) DECAY-DATA (60-ND-139-G,30.0MIN, B+, 0.257,

DG, 405.,0.055)

(60-ND-139-M, 5.5HR， DG, 738.,0.37,

$D G, 982 \ldots 0.29$,

$D G, 708 \ldots 0.27$,

$D G, 403 \ldots 0.03$,

$B+, 0.006)$

${ }^{1}$ Decay data relevant to the monitor reaction are coded under the keyword DECAY-MON and not under DECAY-DATA. 
DECAY-MON. Gives the decay data assumed by the author for any nuclide occurring in the monitor reaction used. The coding rules are the same as those for DECAY-DATA, except that there is no flag field.

DETECTOR. Gives information about the detector(s) used in the experiment. Codes are found in Dictionary 22. If the code COIN is used, then the codes for the detectors used in coincidence follow within the same parenthesis;

Example: DETECTOR (COIN, NAICR, NAICR)

EMS-SEC. Gives information about secondary squared effective mass of a particle or particle system, and to define secondary-mass fields given in the data table. The format of the coded information is: (heading, particle).

Heading Field contains the data heading or the $\operatorname{root}^{2}$ of the data heading to be defined. Particle Field contains the particle or nuclide to which the data heading refers. The code is:

either a particle code from Dictionary 13.

or a nuclide code.

Example: EMS-SEC (EMS1,N)

(EMS2, P+D)

EN-SEC. Gives information about secondary.energies, and to define secondary-energy fields given in the data table. The format of the coded information is: (heading,particle).

Heading Field. Contains the data heading or the root of the data heading to be defined.

Particle Field. Contains the particle or nuclide to which the data heading refers. The code is:

either a particle code from Dictionary 13.

or a nuclide code.

Example: EN-SEC (E1,G)

$(\mathrm{E} 2, \mathrm{~N})$

(E-EXC, 3-LI-7

ERR-ANALYS. Explains the sources of uncertainties and the values given in the COMMON or DATA sections under data headings of the type ERR- or -ERR. The general code format is (heading,correlation factor) free text

Heading Field. Contains the data heading or the root $^{3}$ of the data heading to be defined.

Correlation Factor Field contains the correlation factor, coded as a floating point number.

\section{Example:}

BIB

...

ERR-ANALYS

(EN-ERR) followed by explanation of energy error

(ERR-T) followed by explanation of total uncertainty

(ERR-S) followed by explanation of statistical uncertainty

\footnotetext{
${ }^{2}$ Root means that the data heading given will also define the same heading followed by -MN, -MAX or -APRX.

${ }^{3}$ Root means that the data heading given also defines the heading preceded by + or - .
} 
EXP-YEAR. Defines the year in which the experiment was performed when it differs significantly from the data of the references given (e.g., classified data published years later).

Example: EXP-YEAR (1965)

FACILITY. Defines the main apparatus used in the experiment. The facility code from Dictionary 18 may be followed by an institute code from Dictionary 3, which specifies the location of the facility.

Example: FACILITY (CHOPF, 1USACOL)

(SPECC, 1USABNL)

FLAG. Provides information to specific lines in a data table. See also LEXFOR, Flags.

Example: BIB

$\begin{array}{lll}\cdots & (1 .) \text { Data averaged from } 2 \text { runs } \\ \text { FLAG } & (2 .) \text { Modified detector used at this energy } \\ \text { ENDBIB } & & \\ \ldots & & \\ \text { DATA } & \text { DATA } & \text { FLAG } \\ \text { EN } & \text { MB } & \text { NO-DIM } \\ \text { KEV } & 123 . & 1 . \\ 1.2 & 234 . & \\ 2.3 & 23 . & 2 . \\ 3.4 & 456 . & \end{array}$

HALF-LIFE. Gives information about half-life values and defines half-life fields given in the data table. The general coding format is: (heading,nuclide)

$\begin{aligned} \text { Example: HALF-LIFE } & \text { (HL1, 41-NB-94-G) } \\ & \text { (HL2, 41-NB-94-M) }\end{aligned}$

HISTORY. Documents the handling of an entry or subentry. The general format of the code is: (yyyymmddx), where yyyymmdd is the date (year,month,day) and $x$ is a code from Dictionary 15.

$\begin{array}{ll}\text { Example: HISTORY } & (19940312 \mathrm{C}) \\ & (19960711 \mathrm{~A})\end{array}$ Data units corrected.

INC-SOURCE. Gives information on the source of the incident particle beam used in the experiment. Codes are found in Dictionary 19.

Example: INC-SOURCE (POLNS, D-T)

INC-SOURCE (MPH=13-AL-27 (N, A) 11-NA-24)

INC-SPECT. Provides free text information on the characteristics and resolution of the incident-projectile beam. 
INSTITUTE. Designates the laboratory, institute, or university at which the experiment was performed, or with which the authors are affiliated. Codes are given in Dictionary 3.

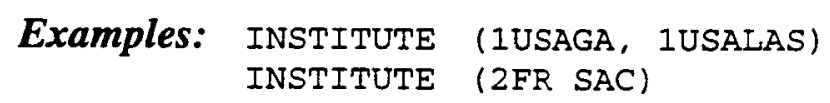

LEVEL-PROP. Gives information on the spin and parity of excited states. The general format of the code is ((flag) nuclide, level identification, lever properties)

Flag. Coded as a fixed-point number that appears in the data section under the data heading LVL-FLAG. When the flag is omitted, its parentheses are also omitted.

Nuclide. Coded is a nuclide, except that the use of the extension $\mathrm{G}$ is optional.

Level identification. Identification of the level whose properties are specified, given as either a level energy or level number. If the field omitted, its separating comma is omitted.

Level Energy. The field identifier $E-L V L=$ followed by the excited state energy in $\mathrm{MeV}$, coded as a floating-point number which also appears in the data section under the data heading E-LVL.

Level Number. The field identifier LVL-NUMB = followed by the level number of the excited state, coded as a fixed-point number which also appears in the data section under the data heading LVL-NUMB.

Level properties. Properties for the excited state, each preceded by a subfield identification. At least one of the fields must be present. If the field is omitted, its separating comma is omitted.

Spin. The field identifier SPIN=, followed by the level spin coded as a floating point number. For an uncertain spin assignment, two or more spins may be given, each separated by a slash.

Parity. The field identifier PARITY $=$, followed by the level parity, coded as e.g., +1 . or -1 .

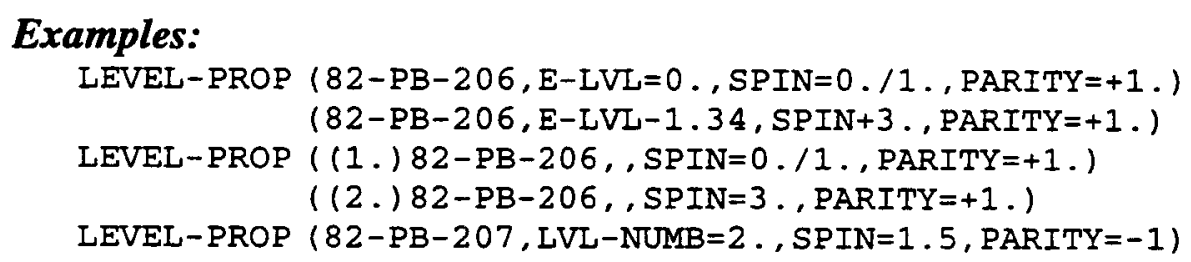

METHOD. Describes the experimental technique(s) employed in the experiment. Codes are found in Dictionary 21.

Example: METHOD (RCHEM) Radiochemical separation

MISC-COL. Defines fields in the COMMON or DATA sections headed by MSC and it derivatives.

Example: MISC-COL (MISC1) Free text describing 1st miscellaneous field

(MISC2) Free text describing 2nd miscellaneous field 
MOM-SEC. Gives information about secondary linear momentum, and defines secondarymomentum fields given in the data table. The general code format is: (heading,particle)

Heading Field: the data heading or root $^{4}$ of the data heading to be defined.

Particle Field: the particle or nuclide to which the data heading refers. The code is:

either a particle code from Dictionary 13.

or a nuclide code.

Example: MOM-SEC (MOM-SEC1,26-FE-56)

(MOM-SEC2, 26-FE-57)

MONITOR. Gives information about the standard reference data (standard, monitor) used in the experiment and defines information coded in the COMMON and DATA sections under the data heading MONIT, etc. The general coding format is ((heading) reaction)

Heading Field. Contains the data heading of the field in which the monitor value is given. If the heading is omitted, its parenthesis is omitted.

Reaction Field. The coding rules are identical to those for REACTION, except that subfields 5 to 9 may be omitted if the reaction is known.

\section{Example:}

$\begin{array}{ll}\text { REACTION } & 1 \text { (AAAAA) } \\ \text { MONITOR } & 2 \text { (BBBBB) } \\ & 1 \text { (CCCCC) } \\ \ldots & 2 \text { (DDDDD) } \\ \text { DATA } & \\ \text { EN } & \text { DATA }\end{array}$

...

1.DATA

2 MONIT

1.MONIT

2

MONIT-REF. Gives information about the source reference for the standard (or monitor) data used in the experiment.

The general code format is ((heading)subaccession\#,author,reference)

Heading Field: Data heading of the field in which the standard value is given. If the heading is omitted, its parentheses are also omitted.

Subaccession Number Field: Subaccession number for the monitor data, if the data is given in an EXFOR entry. Cnnnn001 refers to the entire entry; Cnnnn000 refers to a yet unknown subentry.

Author Field. The first author, followed by " + " when more than one author exists.

Reference Field. May contain up to 6 subfields, coded as under REFERENCE.

\section{Example:}

MONIT-REF ((MONIT1) BOO17005, J .GOSHAL , J , PR, 80, 939, 1950)

( (MONIT2) , A.G.PANONTIN+ , J, JIN, 30, 2017, 1968)

\footnotetext{
${ }^{4}$ Root means that the data heading given will also define the same heading followed by -MN, -MAX or -APRX.
} 
PART=DET. Gives information about the particles detected directly in the experiment. Particles detected in a standard/monitor reaction are not coded under this keyword. The code is either a code from Dictionary 13, or, for particles heavier than $\alpha$ particles, a nuclide code. Particles detected pertaining to different reaction units within a reaction combination are coded on separate records in the same order as the corresponding reaction units.

$$
\begin{array}{lll}
\text { Example: } & \text { PART-DET } & \text { (A) } \\
& \text { PART-DET } & (3-\mathrm{LI}-6)
\end{array}
$$

RAD-DET. Gives information about the decay radiations (or particles) and nuclides observed in the reaction measured. The general format of the code is ((flag)nuclide, radiation).

Flag is a fixed-point number which appears in the data section under the data heading DECAY-FLAG. If the field is omitted, its parentheses are also omitted.

Nuclide contains a nuclide code.

Radiation contains one or more codes from Dictionary 33, each separated by a comma.

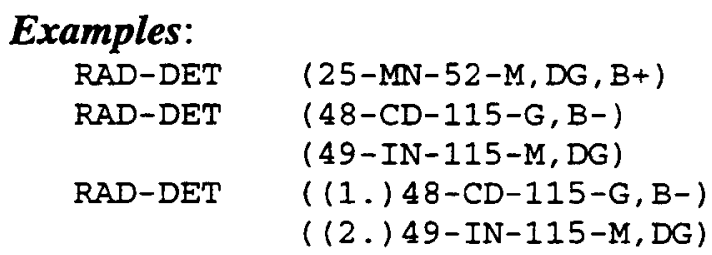

REACTION. Specifies the data presented in the DATA section in fields headed by DATA. ${ }^{5}$ The general format of the code is (reaction, quantity, data-type).

Reaction field. The reaction field consists of 4 subfields.

SF1. Target nucleus. Contains either:

a) a nuclide code.

$\mathrm{A}=0$ denotes natural isotopic abundance.

b) a compound code.

c) a variable nucleus code ELEM and/or MASS

Example: (ELEM/MASS (0, B-), , PN)

SF2. Incident projectile. Contains one of the following:

a) a particle code from Dictionary 28 .

b) for particles heavier than an $\alpha$, a nuclide code.

SF3. Process. Contains one of the following:

a) a process code from Dictionary 30, e.g., TOT.

b) a article code from Dictionary 29 which may be preceded by a multiplicity factor, whose value may be $2 \rightarrow 99 .^{6}$, e.g., $4 \mathrm{~A}$.

\footnotetext{
5 And similar headings such as DATA-MN, DATA-MAX, etc.

${ }^{6}$ In the few cases where the multiplicity factor may exceed 99, the Variable Number of Emitted Nucleons

Formalism may be used, see page 6.7 .
} 
c) for particles heavier than $\alpha$, a nuclide code.

Examples: $\quad 8-0-16$

$8-0-16+8-0-16$

d) combinations of a), b) and c), with the codes connected by ' + '.

Examples: $\mathrm{HE} 3+8-0-16$

$\mathrm{A}+\mathrm{XN}+\mathrm{YP}$

If SF5 contains the branch code UND ${ }^{7}$ (undefined), the particle codes given in SF3 represent only the sum of emitted nucleons, implying that the product nucleus coded in SF4 has been formed via different reaction channels. The code (DEF) in SF5 denotes that it is not evident from the publication whether the reaction channel is undefined or defined.

SF4. Reaction Product. In general, the heaviest of the products is defined as the reaction product (also called residual nucleus). In the case of two reaction products with equal mass, the one with the larger $Z$ is considered as the heavier product. Exceptions or special cases are:

- If SF5 contains the code SEQ, indicating that the sequence of several outgoing particles and/or processes coded in SF3 is meaningful, the nuclide to be coded in SF4 is the heaviest of the final products.

Example: $\quad(5-\mathrm{B}-10(\mathrm{~N}, \mathrm{~A}+\mathrm{T}) 2-\mathrm{HE}-4, \mathrm{SEQ}, \mathrm{SIG})$

- Where emission cross sections, production cross sections, product yields, etc., are given for specified nuclides, particles, or gammas, the product considered is defined as the reaction product (even if it is not the heaviest of several reaction products).

This subfield contains:

either a blank,

Example: (26-FE-56 (N, EL), ,WID)

or a nuclide code.

Example: (51-SB-123 (N, G) 51-SB-124-M1+M2/T)

or, a variable nucleus codes:

Example: (92-U-235 (N, F) ELEM/MASS, CUM, FY)

Quantity consists of four subfields, each separated by a comma. All combinations of codes allowed in the quantity field are given in Dictionary 36.

SF5 Branch. Indicates a partial reaction, e.g., to one of several energy levels.

SF6 Parameter. Indicates the reaction parameter given, e.g., differential cross section.

\footnotetext{
${ }^{7}$ The code UND is presently used only for charged particle reaction data.
} 
SF7 Particle Considered. Indicates to which of several outgoing particles the quantity refers. ${ }^{8}$ Multiple codes, e.g., for the correlation between outgoing particles, all particles are separated by a slash.

SF8 Modifier. Contains information on the representation of the data, e.g., relative data.

Data Type Field. Indicates whether the data are experimental, theoretical, evaluated, etc. Codes are found in Dictionary 35.

Variable Nucleus. For certain processes, the data table may contain yield or production cross sections for several nuclei which are entered as variables in the data table. In this case, either SF1 or SF4 of the REACTION keyword contain one of the following codes:

ELEM - if the $Z$ (charge number) of the nuclide is given in the data table.

MASS - if the A (mass number) of the nuclide is given in the data table.

ELEM/MASS - if the $\mathrm{Z}$ and $\mathrm{A}$ of the nuclide are given in the data table.

The nuclei are entered in the common data or data table as variables under the data headings ELEMENT and/or MASS with the units NO-DIM.

If the data headings ELEMENT and MASS are used, a third field with the data heading ISOMER is used when isomer states are specified:

0. = ground state (used only if nuclide has also an isomeric state),

1. = first metastable state (or the metastable state when only one is known),

2. = second metastable state, etc.

Decay data for each entry under ELEMENT/MASS(ISOMER) and their related parent or daughter nuclides may be given in the usual way under the information-identifier keyword DECAYDATA. Entries under the data headings ELEMENT/MASS(ISOMER) are linked to entries under DECAY-DATA (and RAD-DET, if present) by means of a decay flag. ${ }^{9}$

\section{Example:}
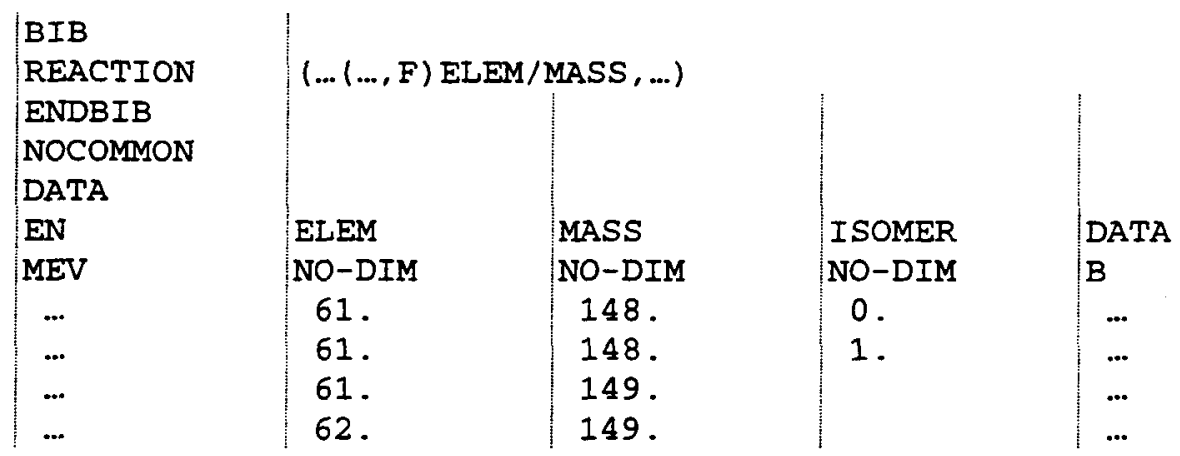

\footnotetext{
${ }^{8}$ Note that the particle considered is not necessarily identical to the particle detected, e.g., the angular distribution of an outgoing particle which has been deduced from a recoil particle detected.

9 If the half-life is the only decay data given, this may be entered in the data table under the data heading $\mathrm{HL}$, although this is not recommended.
} 
Variable Number of Emitted Nucleons. Where mass and element distributions of product nuclei have been measured, the sum of outgoing neutrons and protons may be entered as variables in the data table. In this case SF3 of the REACTION keyword contains at least one of the following codes:

$\mathrm{XN}$ - variable number of neutrons given in the data table.

YP - variable number of protons given in the data table.

The numerical values of the multiplicity factors $X$ and $Y$ are entered in the data table under the data headings N-OUT and P-OUT, respectively.

\section{Example:}

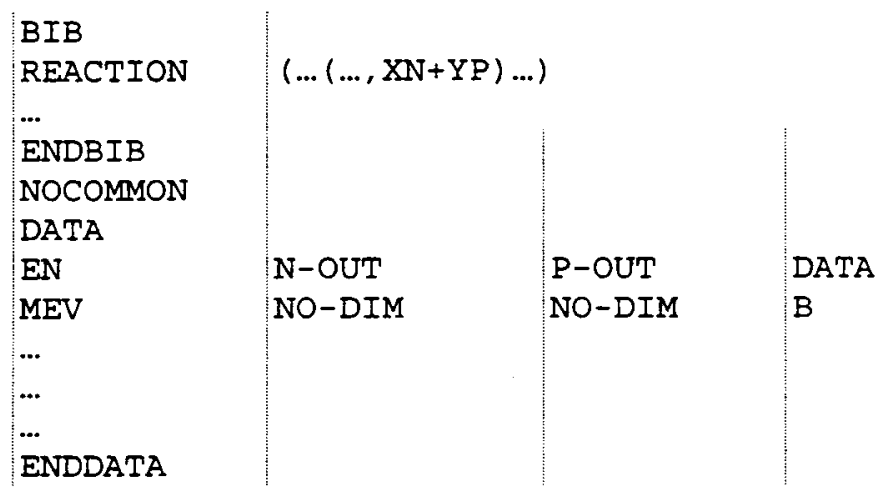

Reaction Combinations. For experimental data sets referring to complex combinations of materials and reactions, the code units defined in this section can be connected into a single machine-retrievable field, with appropriate separators and properly balanced parentheses. The complete reaction combination is enclosed in parentheses.

The following reaction combinations are defined:
$((----)+(----))$
Sum of 2 or more quantities (see LEXFOR, Sums).
$((----)-(---)))$
Difference between 2 or more quantities.
$((----) *(----))$
Product of 2 or more quantities (see LEXFOR, Products).
$((---)) /(----))$
Ratio of 2 or more quantities (see LEXFOR, Ratios).
$((-----) / /(----))$
Ratio of 2 quantities, where the numerator and denominator refer to different values for one or more independent variables (see LEXFOR, Ratios).
$((-----)=(----))$
Tautologies (see LEXFOR, Tautologies for usage).

When a reaction combination contains the separator "//", the data table will contain at least one independent variable pair with the data heading extensions -NM and -DN. 


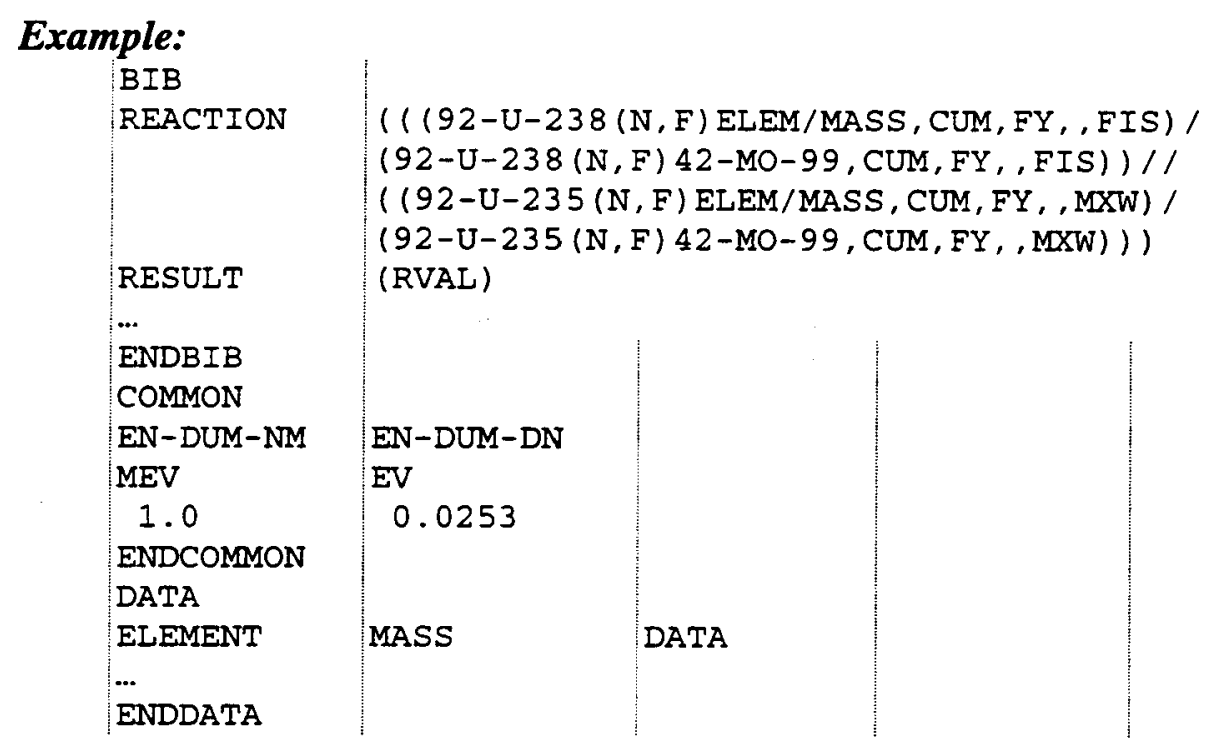

REFERENCE. Gives information on references that contain information about the data coded. Other related references are not coded under this keyword (see REL-REF, MONIT-REF). The general coding format is (reference type, reference, date).

The format of the reference field is dependent on the reference type. The general format for each reference type follows.

Type of Reference $=\mathrm{B}$ or $\mathrm{C}$; Books and Conferences.

General code format: (B or C,code,volume,(part),page(paper \#),date). Codes from Dictionary 7. Examples:

(C, 67KHARKOV, , (56), 196702) Kharkov Conference Proceedings, paper \#56, February 1967.

(C, 66WASH, 1, 456, 196603) Washington Conference Proceedings, Volume 1, page 456, March 1966

(B, ABAGJAN, , 123, 1964) Book by Abagjan, page 123, published in 1964.

Type of Reference $=\mathrm{J}$ : Journals.

General code format is (J,code,volume,(issue \#),page,date). Codes are from Dictionary 5.

Examples:

( $\mathrm{J}, \mathrm{PR}, 104,1319,195612$ )

Phys. Rev. Volume 104, page 1319, December 1956

$(\mathrm{J}, \mathrm{XYZ}, 5,(2), 89,196602)$

Journals XYZ, Volume 5, issue \#2, page 89, February 1966

Type of Reference $=\mathrm{P}$ or R or $\mathrm{S}$; Reports.

General code format: (P or R or S,code-number,date). Codes from Dictionary 6. Examples:

(R, JINR-P-2713, 196605)

Dubna report, series P, number 2713, May 1966.

(P, WASH-1068,185,196603)

WASH progress report number 1068, page 185, March 1966. 
Type of Reference $=T$, or $W$; Thesis or Private Communication.

General code format: (W or T,author,page,date)

Examples:

(W, BENZI, 19661104)

private communication from Benzi, November 4, 1966.

( $T$, ANONYMOUS, 58,196802 ) thesis by Anonymous, page 58, February 1968.

REL-REF. Gives information on references related to, but not directly pertaining to, the work coded. The general code format is: (code,subaccession\#,author,reference).

Code: code from Dictionary 17.

Subaccession \#: EXFOR subaccession number for the reference given, if it exists. Cnnnn001 refers to the entire entry Cnnnn. Cnnnn000 refers to a yet unassigned subentry within the entry Cnnnn.

Author: first author, coded as under AUTHOR, followed by + when more than one author exists.

Reference: coded as for REFERENCE.

\section{Example:}

(C, B9999001, A.B.NAME+,J,XYZ,5, (2),90,197701) Critical remarks by A.B.Name, et al., in journal XYZ, volume 5, issue \#2, p. 90, January 1977.

RESULT. Describes commonly used quantities that are coded as REACTION combinations.

$\begin{array}{rll}\text { Example: } & \text { REACTION } & ((Z-S-A(N, F) \text { ELEM } / M A S S, C U M, F Y) / \\ & (Z-S-A(N, F) M A S S, C H N, F Y)) \\ & \text { RESULT } & (F R C U M)\end{array}$

SAMPLE. Used to give information on the structure, composition, shape, etc., of the measurement sample.

STATUS. Givews information on the status of the data presented. Entered in one of the general code formats, or for cross reference to another data set, the general code format is: (code,subaccession\#)

Code: code from Dictionary 16.

- Subaccession\# Field: cross-reference to an EXFOR subaccession number, see REL-REF.

Example:

STATUS (SPSDD, 10048009) - this sưbentriry is superseded by subentry 10048009.

TITLE. Gives the title for the work referenced. 


\section{Appendix C}

\section{COVARIANCE DATA FILE FORMAT}

Where covariance files are large, the covariance data may be stored in a separate covariance file. The existance of the file will be indicated in the corresponding EXFOR data set under the information-identifier keyword COVARIANCE, see Appendix B, COVARIANCE.

There are three record types in the covariance file:

- comment records,

- data records,

- end records.

\section{Comment record format}

Column

$1+C$

2-9 Data set number (subaccession number)

10 (blank)

11 - 80 Comment which includes covariance type and format

\section{Data record format}

Column

1

$2-9$

10

$11-80$
D

Data set number (subaccession number) (blank)

Data in format given on comment record

\section{End record format}

$\begin{array}{rrrl}\text { Column } & 1 & & \text { E } \\ & 2-9 & \text { Data set number (subaccession number) } \\ & 10-80 & \text { (blank) }\end{array}$




\section{Appendix D}

\section{Table of Dictionaries}

The EXFOR System Dictionaries list all keywords and codes used in the EXFOR entries. Listings are included for the following dictionaries. Where the dictionary is large, the most used codes are given. A complete listing of all dictionaries and codes is available from any of the Nuclear Reaction Data Centers.

Dictionary 3. Institutes

Page

Dictionary 4. Reference Type

D. 3

Dictionary 5. Journals

D.7

Dictionary 7. Conference and Books.

D.7

Dictionary 15 . History

D. 10

Dictionary 16. Status.

D. 12

Dictionary 17. Rel-Ref.

D. 13

Dictionary 18 . Facility

D. 13

Dictionary 19. Incident Source

D. 14

Dictionary 20. Additional Results

D. 15

Dictionary 21. Method

D. 16

Dictionary 22. Detectors

Dictionary 23. Analysis

D.19

Dictionary 24. Data Headings

D. 20

Dictionary 30. Process

Dictionary 33. Particles

D.22

Dictionary 34. Modifiers (REACTION SF8)

D. 23

Dictionary 35. Data-Type (REACTION SF9)

D. 24

Dictionary 36. Quantities (REACTION SF5-7)

D. 25

Dictionary 37. Result

D. 26

D.30 
Dictionary 3. Institutes: used with the keywords INSTITUTE and FACILITY. The first character of the codes designates the area of responsibility (see Appendix A), the next three characters designate the country, and the last three characters specify the institute. A subset containing some of the most frequently used codes is given here.

Area 1: United States and Canada

Canada

1CANCRC

1CANMCM

1CANTMF

United States

IUSAANL

IUSAARK

IUSABNL

IUSABNW

IUSABRK

IUSACOL

IUSADAV

IUSADKE

IUSAFSU

IUSAGEO

IUSAGGA

IUSAGIT

IUSAHAN

IUSAINL

IUSAINU

IUSAKAP

IUSAKTY

IUSALAS

IUSALRL

1USALTI

IUSAMHG

IUSAMIT

IUSAMRY

1USANBS

1USANIS

IUSANOT

IUSAOHO

IUSAORL

IUSARPI

IUSATEX

1USATNL

IUSAWIS
A.E.C.L., Chalk River, Ontario

McMaster University, Hamilton, Ontario

Tri University Meson Facility, Vancouver, B.C.

Argonne National Laboratory, Argonne, IL

Univ. of Arkansas, Fayetteville, AR

Brookhaven National Laboratory, Upton, NY

Pacific Northwest Laboratories, Richland, WA

Univ. of Calif. Lawrence Berkeley Lab., Berkeley, CA

Columbia University, New York, NY

University of California, Davis, CA

Duke University, Durham, NC

Florida State University, Tallahasse, FL

University of Georgia, Athens, GA

Gulf General Atomic, San Diego, CA

Georgia Institiute of Technology, Atlanta, GA

Hanford Atomic Products, Richland, WA

Idaho Nuclear Engineering Lab., Idaho Falls, ID

Indiana University, Bloomington, IN

Knolls Atomic Power Laboratory, Schenectady, NY

University of Kentucky, Lexington, KY

Los Alamos National Laboratory, NM

Lawrence Livermore National Laboratory, Livermore, CA

University of Lowell, Lowell, MA

University of Michigan, Ann Arbor, MI

Massachusetts Institute of Technology, Cambridge, MA

University of Maryland, College Park, MD

National Bureau of Standards, Washington, DC

National Inst.of Standards \& Techn., Gaithersburg, MD

Univ. of Notre Dame, Notre Dame, IN

Ohio University, Athens, $\mathrm{OH}$

Oak Ridge National Laboratory, Oak Ridge, TN

Rensselaer Polytechnic Institute, Troy, NY

Univ. of Texas, Austin, TX

Triangle Universities Nuclear Lab., Durham, NC

University of Wisconsin, Madison, WI 


\section{Area 2: OECD Countries}

Austria

2AUSIRK Inst. fuer Radiumforschung und Kernphysik, Vienna

Belgium

2BLGMOL C.E.N., Mol

Denmark

2DENRIS Riso, Roskilde

Finland

France

2SF JYV Jyvaeskylae Univ., Jyvaeskylae

2FR BRC

2FR CAD

CEN Bruyere-le-Chatel

2FR FAR

C.E.N. Cadarache

2FR GRE

CEA Fontenay-aux-Roses, Seine

Grenoble, Isere, (CEA and Univ.)

2FR PAR

2FR SAC

Univ. of Paris, (incl.Orsay), Paris

C.E.N. Saclay

Germany

2GERFRK

J.W.Goethe Univ.,Frankfurt

2GERGSI

2GERHAM

Gesellschaft fuer Schwerionenforschung, Darmstadt

2GERJUL

2GERKFK

Hamburg, Universitaet

Kernforschungsanlage Juelich

2GERKIL

2GERMUN

Kernforschungszentrum, Karlsruhe

Univ. of Kiel, Kiel

Technische Universitaet Muenchen

2GERPTB

Phys.Techn.Bundesanst., Braunschweig

Greece

2GERZFK

Zentralinst.f.Kemforschung, Rossendorf

2GRCATH

Italy

2ITYBOL

2ITYCAT

2ITYPAD

Japan

2JPNJAE

2JPNKTO

2JPNKYU

2JPNOSA

2JPNTIT

2JPNTOH

2JPNTOK

The Netherlands

2NEDGRN

2NEDRCN

Norway

2NORKJL

CNRC Demokritos, Athens

ENEA Centro Ricerche Energia di Bologna

Univ. of Catania

Padua, University and Lab. Nat. Legnaro

JAERI, Tokai

Kyoto Univ., Kyoto

Kyushu Univ., Dept.of Nucl.Eng., Fukuoka

Osaka Univ., Osaka

Tokyo Inst.of Technology, Tokyo

Tohoku Univ., Sendai

Tokyo Univ., Tokyo

Groningen

Netherland's Energy Research Foundation, Petten

Inst. foer Atomenergi, Kjeller 
Sweden

2SWDAE Studsvik Energiteknik AB

2SWDFOA Research Inst. for National Defence, Stockholm

Switzerland

2SWTETH Eidgenossische Technische Hochschule, Zuerich

2SWTPSI Paul Scherrer Inst., Villigen

United Kingdom

2UK ALD Awre, Aldermaston, England

2UK DOU

Dounreay Experimental Reactor Establishment, England

2UK HAR

2UK NPL

AERE, Harwell, Berks, England

2UK OXF

National Phys.Lab., Teddington, England

Univ. of Oxford, Oxford, England

Area 3: Remaining countries outside other 3 areas

Australia

3AULAML Univ. of Melbourne, Melbourne

3AULAUA

Australian Nucl. Sci. and Techn.Org., Lucas Heights, SW

3AULCBR

Australian National Univ., Canberra

China

3CPRAEP

3CPRBJG

3CPRLNZ

3CPRNIX

3CPRNRS

3CPRSST

3CPRTSI

Croatia

3CRORBZ

3CROZAG

Czechoslovakia

3CZRUJV

Hungary

3HUNDEB

3HUNKFI

3HUNKOS

India

3INDBOS

3INDMUA

3INDSAH

3INDTAT

3INDTRM

Israel

3ISLNEG

3ISLWEI

Inst. of Atomic Energy, Beijing

Beijing Univ., Beijing

Lanzhou Univ., Lanzhou

Northwest Inst.of Nucl.Technology, Xian

Inst.of Nucl.Research, Acad.Sinica, Shanghai

Shanghai Univ. of Science and Technology

Tsinghua Univ., Beijing

Inst.Rudjer Boskovic, Zagreb

Univ. of Zagreb, Zagreb

Inst. of Nuclear Research, Rez i Prahy

Inst.of Nuclear Research, ATOMKI, Debrecen

Central Research Inst. for Physics, KFKI, Budapest

Inst. for Experimental Physics, Kossuth U., Debrecen

Bose Institute, Calcutta

Muslim Univ., Aligarh

Saha Institute, Calcutta

Tata Institute, Bombay

Bhabha Atom.Res.Centre, Trombay

Ben Gurion Univ. of the Negev, Beer-Sheva

Weizmann Inst., Rehovoth 
Mexico

3MEXUMX Univ. Nacionale Autonoma de Mexico, Mexico City

New Zealand

3NZLNZH Inst.of Nuclear Sciences, Lower Hutt

Poland

3POLIPJ Soltan Inst.Probl.Jadr., Swierk+Warszawa

3POLWWA Warszawa, University

Romania

3RUMBUC Inst. de Fizica si Inginerie Nucleara, Bucharest

South Africa

3SAFPEL

Atomic Energy Corp.of South Africa, Pelindaba

Area 4: Russian Federation

Armenia

4ARMJER Inst. Fiziki Armenian A.N., Jerevan

Belorus

4BLRIJE Inst. Yad. Energetiki A.N.Byeloruss.SSR, Minsk

Kazakhstan

4KASKAZ Inst.Yadernoi Fiziki, Alma-Ata

Latvia

4LATIFL Inst. Fiziki Latviyskoi A.N., Riga

Russia

4RUSEPA Experimental Physics Inst., Arzamas

4RUSFEI Fiziko-Energeticheskii Inst., Obninsk

4RUSFTI Fiz.-Tekhnicheskiy Inst.Ioffe, St.Petersburg+Gatchina

4RUSICP Inst.of Chemical Phys., Moscow

4RUSITE Inst.Teoret.+ Experiment. Fiziki, Moscow

4RUSJIA Inst.Yadernych Issledovaniy Russian Acad. Sci.

4RUSKUR Inst.At.En. I.V.Kurchatova, Moscow

4RUSLEB Fiz.Inst. Lebedev (FIAN), Moscow

4RUSLIN Leningrad Inst.Nucl.Phys., Russian Acad.Sci., Gatchina

4RUSMOS Moscow State Univ., Nuclear Physics Inst., Moscow

4RUSNIR NIIAR Dimitrovgrad

4RUSRI Khlopin Radiev.Inst., Leningrad

Ukraine

4UKRIJI

4UKRKFT

Inst. Yadernykh Issledovaniy Acad. Sct. Ukraine, Kiev

4UKRKGU

International

Kharkovskii Fiziko-Tekhnicheskii Inst., Kharkov

Gosudarstvennyi Univ.(State Univ.), Kiev

4ZZZDUB

Joint Inst.for Nucl.Res., Dubna 
Dictionary 4: Reference type: used as the first subfield for the keyword REFERENCE, and, similarly, for MONIT-REF, and REL-REF.

$\begin{array}{ll}\text { B } & \text { Book } \\ \text { C } & \text { Conference } \\ \text { J } & \text { Journal } \\ \text { P } & \text { Progress report } \\ \text { R } & \text { Report other than progress report } \\ \text { S } & \text { Report containing conference proceedings } \\ \text { T } & \text { Thesis or dissertation } \\ \text { W } & \text { Private communication }\end{array}$

Dictionary 5: Journal codes: used as the second subfield for the keyword REFERENCE, when the reference type is given as J; similarly, for MONIT-REF, and REL-REF. A subset containing some of the most frequently used codes is given here. The code may have an extension delimited by a slash; these extensions have the following meanings:

$/ A, / B, \ldots, / G$ section or series

A letters section

IS supplement

$\begin{array}{ll}\text { ACR } & \text { Acta Crystallographica } \\ \text { ADP } & \text { Annalen der Physik } \\ \text { AE } & \text { Atomnaya Energiya } \\ \text { AEJ } & \text { Journal of the Atomic Energy Society of Japan } \\ \text { AF } & \text { Arkiv foer Fysik } \\ \text { AHP } & \text { Acta Physica Hungarica } \\ \text { AJ } & \text { Astrophysical Joumal } \\ \text { AK } & \text { Atomki Kozlemenyek } \\ \text { AKE } & \text { Atomkernenergie } \\ \text { ANP } & \text { Annalen der Physik (Leipzig) } \\ \text { ANS } & \text { Transactions of the American Nuclear Society } \\ \text { AP } & \text { Annals of Physics (New York) } \\ \text { APA } & \text { Acta Physica Austriaca } \\ \text { APP } & \text { Acta Physica Polonica } \\ \text { ARI } & \text { Applied Radiation and Isotopes } \\ \text { AUJ } & \text { Australian Joumal of Physics } \\ \text { BAP } & \text { Bulletin of the American Physical Society } \\ \text { BAS } & \text { Bull.Russian Academy of Sciences - Physics } \\ \text { CHP } & \text { Chinese Journal of Physics (Taiwan) } \\ \text { CJP } & \text { Canadian Journal of Physics } \\ \text { CR } & \text { Comptes Rendus } \\ \text { CZJ } & \text { Czechoslovak Journal of Physics } \\ \text { DOK } & \text { Doklady Akademii Nauk } \\ \text { EPJ } & \text { European Physics Journal } \\ \text { FIZ } & \text { Fizika }\end{array}$




\begin{tabular}{|c|c|}
\hline HPA & Helvetica Physica Acta \\
\hline LJP & Indian Journal of Physics \\
\hline INC & Inorganic and Nuclear Chemistry Letters \\
\hline ISP & Israel J.of Physics \\
\hline IZV & Izv.Rossiiskoi Akademii Nauk,Ser.Fiz. \\
\hline JAE & Yadernaya Energetika \\
\hline JEL & Soviet Physics - JETP Letters \\
\hline JET & Soviet Physics - JETP \\
\hline JIN & Journal of Inorganic and Nuclear Chemistry \\
\hline JNE & Journal of Nuclear Energy \\
\hline JP & Jour. of Physics \\
\hline JPJ & Journal of the Physical Society of Japan \\
\hline JPR & Journal de Physique (Paris) \\
\hline JRC & J.of Radioanalytical Chemistry \\
\hline JRN & J.of Radioanalytical and Nuclear Chemistry \\
\hline KFI & KFKI Kozlemenyek \\
\hline $\mathrm{NC}$ & Nuovo Cimento \\
\hline NCL & Lettere al Nuovo Cimento \\
\hline NCR & Rivista del Nuovo Cimento \\
\hline NCS & Nuovo Cimento, Suppl. \\
\hline NIM & Nuclear Instrum.and Methods in Physics Res. \\
\hline NKA & Nukleonika \\
\hline NP & Nuclear Physics \\
\hline NSE & Nuclear Science and Engineering \\
\hline NST & J.of Nuclear Science and Technology, Tokyo \\
\hline NWS & Naturwissenschaften \\
\hline PAN & Physics of Atomic Nuclei \\
\hline PCJ & Journal of Physical Chemistry \\
\hline PHE & High Energy Physics and Nucl.Physics, Chinese ed. \\
\hline PHY & Physica (Utrecht) \\
\hline PL & Physics Letters \\
\hline PNE & Progress in Nuclear Energy \\
\hline PPS & Proceedings of the Physical Society (London) \\
\hline PR & Physical Review \\
\hline PRL & Physical Review Letters \\
\hline PRS & Proc. of the Royal Society (London) \\
\hline PS & Physica Scripta \\
\hline PTE & Pribory i Tekhnika Eksperimenta \\
\hline $\mathrm{RCA}$ & Radiochimica Acta \\
\hline RJP & Romanian Journal of Physics \\
\hline RRL & Radiochem.and Radioanal.Letters \\
\hline RRP & Revue Roumaine de Physique \\
\hline SJA & Soviet Atomic Energy \\
\hline SJPN & Soviet Journal of Particles and Nuclei \\
\hline SPC & Soviet Physics-Cristallography \\
\hline
\end{tabular}


SPD Soviet Physics-Doklady

UFZ Ukrainskii Fizichnii Zhurnal

UPJ Ukrainian Physics Journal

YF Yadernaya Fizika

YK

Vop. At.Nauki i Tekhn.,Ser.Yadernye Konstanty

ZEP Zhurnal Eksper. i Teoret. Fiz., Pisma v Redakt.

ZET Zhurnal Eksperimental'noi i Teoret. Fiziki

ZP

Zeitschrift fuer Physik 
Dictionary 7: Books and Conferences: used as the second subfield for the keyword REFERENCE, when the reference type is given as B or C, and similarly, for MONIT-REF, and REL-REF. A subset containing some of the most frequently used codes is given here.

Books

ACT.EL Actinide Elements

EXP.NUC.P. Experimental Nuclear Physics

FAST N.PH. Fast Neutron Physics

NB.GS.COMP Noble Gas Compounds, Chicago Press 1963

NEJTRONFIZ Neitronnaya Fizika, Moskva 1961

PR.NUC.EN. Progress in Nucl.Energy

RCS Radiochemical Studies, Fission Products

SPN Sov.Progr.in Neutr.Phys.,New York 1961

TRANSU.EL. Transuranium Elements

Conferences

55GENEVA 1st Conf. on Peaceful Uses Atomic Energy, Geneva 1955

55MOSCOW USSR Conf. Peaceful Uses of Atomic Energy, Moscow 1955

56KIEV Kiev Conf., Kiev 1956

58GENEVA 2nd Conf. on Peaceful Uses Atomic Energy, Geneva 1958

58PARIS Nuclear Physics Congress, Paris 1958

59CALCUTTA Low Energy Nuclear Physics Symp., Calcutta 1959

59LONDON Conf.Nuclear Forces and Few-Nucleon Problem, London 1959

60BASEL

Conf. on Polarization Phenom. in Nuclear Reactions, Basel 1960

60VIENNA Pile Neutron Research Symp., Vienna 1960

60WIEN Neutron Inelastic Scattering Symp., Vienna 1960

61BOMBAY Nuclear Physics Symp., Bombay 1961

61BRUSSELS Neutron Time-of-Flight Colloquium, Brussels 1961

61DUBNA

61MANCH

61RPI

Slow Neutron Physics Conf., Dubna 1961

Rutherford Conf., Manchester 1961

61SACLAY

Neutron Physics Symp., Rensselaer Polytech 1961

62PADUA

Time of Flight Methods Conf., Saclay 1961

63BOMBAY

63KRLSRH

Nucl. Reaction Mechanisms Conf., Padua 1962

Neutron Physics Conf., Karlsruhe 1963

64BOMBAY Neutron Inelastic Scattering Symp., Bombay 1964

64GENEVA

64PARIS

3rd Conf. on Peaceful Uses Atomic Energy, Geneva 1964

65CALCUTTA Nuclear and Solid State Phys.Symp., Calcutta 1965

65KRLSRH Pulsed Neutron Symp., Karlsruhe 1965

65SALZBURG Physics and Chemistry of Fission Conf., Salzburg 1965

66BOMBAY Nuclear and Solid State Physics Symp., Bombay 1966

66GATLNBG Int. Conf. on Nuclear Physics, Gatlinburg, 1966

66MOSCOW Nuclear Spectroscopy Conf., Moscow 1966

66PARIS

Nuclear Data For Reactors Conf., Paris 1966 
66WASH

67BRELA

67JUELICH

67KARLSR

68BOMBAY

68COPENHGN

68MADRAS

68WASH

69ROORKEE

69VIENNA

70ANL

70HELSINKI

70MADISON

70MADURAI

$71 \mathrm{KIEV}$

$71 \mathrm{KNOX}$

72BOMBAY

72GRENOBLE

72KIEV

73BANGLO

73KIEV

73MUNICH

73PACIFI

73PARIS

74BOMBAY

74PETTEN

75CALCUTTA

75KIEV

75WASH

75ZURICH

76AHMEDABA

76LOWELL

77BNL

$77 \mathrm{KIEV}$

77NBS

77VIENNA

$78 \mathrm{BNL}$

78BOMBAY

78HARWELL

79JUELICH

79KNOX

79MADRAS

79SMOLENIC

80BERKELEY

80BNL
Neutron Cross-Section Technology Conf., Washington 1966

Light Nuclei Symp., Brela 1967

Neutron Physics at Reactors Conf., Juelich 1967

Symp. on Fast Reactor Physics,Karlsruhe 1967

Nuclear and Solid State Physics Symp., Bombay 1968

Neutron Inelastic Scattering Symp., Copenhagen 1968

Nuclear and Solid State Physics Symp., Madras 1968

Nuclear Cross-Sections \& Technology Conf., Washington 1968

Nuclear and Solid State Physics Symp., Roorkee 1969

Physics and Chemistry of Fission Symp., Vienna 1969

Neutron Standards Symp., Argonne 1970

Nuclear Data for Reactors Conf., Helsinki 1970

Polarization Phenomena Conf., Madison 1970

Nuclear and Solid State Physics Symp., Madurai 1970

Neutron Physics Conf., Kiev 1971

Conf. Neutron Cross Sections \& Techology, Knoxville 1971

Nuclear and Solid State Physics Symp, Bombay 1972

Neutron Inelastic Scattering Symp., Grenoble 1972

Nuclear Spectroscopy Conf, Kiev 1972

Nuclear and Solid State Physics Symp.,Bangalore, 1973

Conf.on Neutron Physics, Kiev 1973

Conf. on Nuclear Physics,Munich 1973

Conf. on Photonuclear Reactions, Pacific Grove 1973

Applications of Nuclear Data Symp., Paris 1973

Nuclear and Solid State Physics Symp., Bombay 1974

Symp. on Neutron Capture Gamma Ray Spectroscopy, Petten 1974

Nuclear and Solid State Physics Symp.,Calcutta,1975

Conf. on Neutron Phys., Kiev 1975

Conf. on Nuclear Cross Sections and Technology, Washington 1975

Symp. on Polarization Phenomena, Zuerich 1975

Nuclear Physics \& Solid State Physics Symp., Ahmedabad,1976

Conf. on Interaction of Neutrons with Nuclei, Lowell 1976

Symp. on Neutron Cross Sections at 10 - $40 \mathrm{Mev}$, Brookhaven 1977

Conf. on Neutron Physics, Kiev 1977

Symp.on Neutron Standards, Gaithersburg 1977

Symp. on Neutron Inelastic Scattering, Vienna 1977

Symp. on Neutron Capture Gamma Ray Spectroscopy, Brookhaven 1978

Nuclear Physics and Solid State Physics Symp., Bombay 1978

Conf. on Neutron Physics and Nuclear Data, Harwell 1978

Symp. on Physics and Chemistry of Fission, Juelich 1979

Conf. on Nuclear Cross Sections fro Technology, Knoxville 1979

Nuclear Physics and Solid State Physics Symp., Madras 1979

Symp. on Neutron Induced Reactions, Smolenice 1979

Conf. on Nuclear Physics, Berkeley 1980

Symp. on Neutron Cross Sections at 10-50 MeV, Brookhaven 1980 


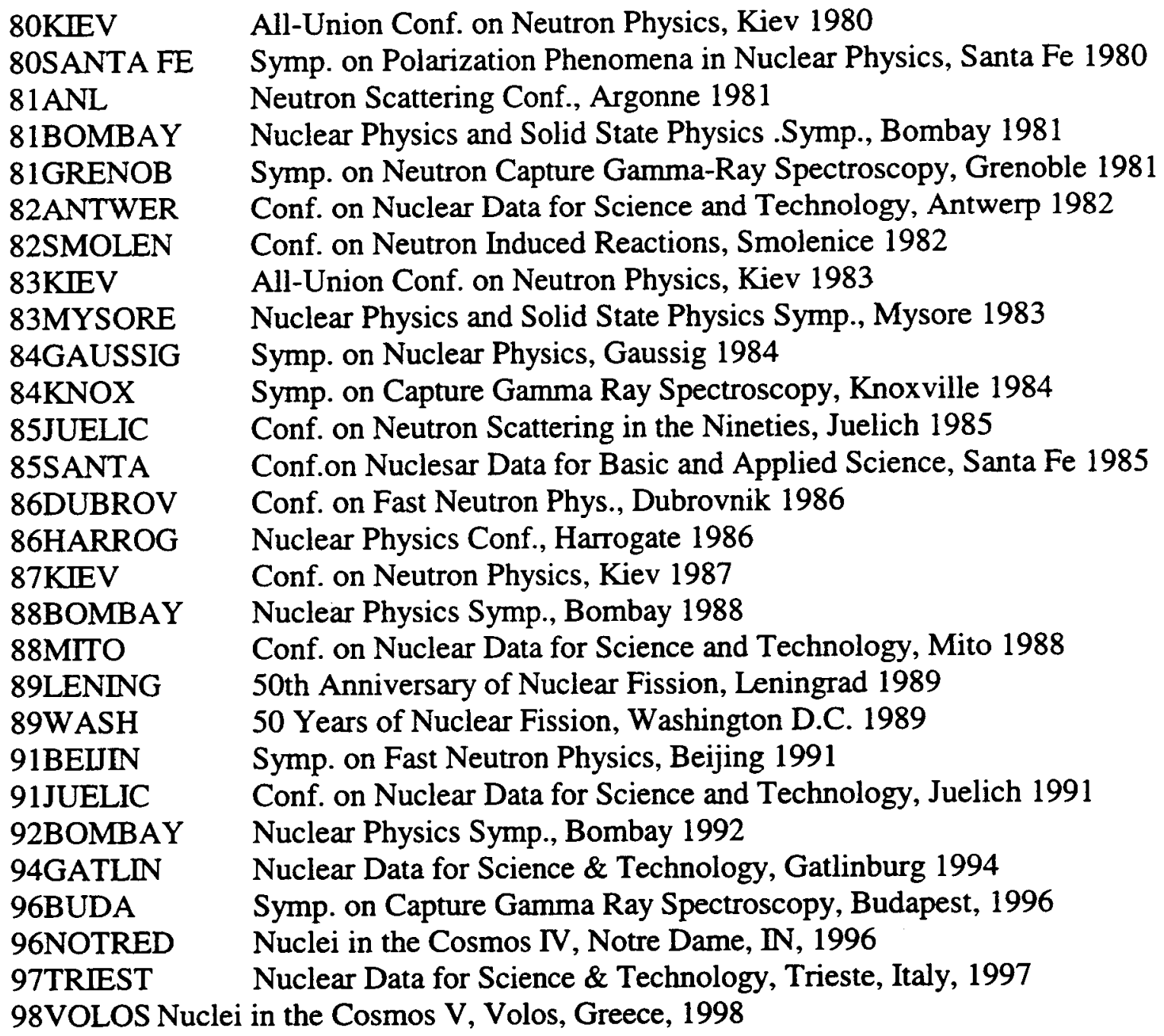

Dictionary 15: History codes:: used with the keyword HISTORY.
A Important alterations
C Complied at the data center
D Entry or subentry deleted
E Transmitted to other data centers
L Entered into data library
$\mathrm{R} \quad$ Data received at the data center
$\mathrm{T}$ Converted from previous compilation
U Unimportant alterations 
Dictionary 16: Status codes: used with the keyword STATUS.
APRVD
Approved by author
COREL
Data correlated with another data set
CPX
Data taken from data file of McGowan, et al.
CURVE
Data read from a curve
DEP
Dependent data
NCHKD
Original reference not checked
NDD
OUTDT
PRELM
Data converted from NEUDADA file
RIDER
Normalization out-of-date
Preliminary data
RNORM
Data converted from file of B.F. Rider
SCSRS
SPSDD
Data renormalized by other than author
Data converted from SCISRS file
Data superseded
TABLE
Data received by center in tabular form
UNOBT
Data unobtainable from author

Dictionary 17: Related Reference codes: used with the keyword REL-REF.
A Reference with which data agree
C Critical remarks
D Reference with which data disagree
E Reference used in the evaluation
N $\quad-$
$\mathrm{R} \quad$ Reference from which data were used 
Dictionary 18: Facility codes: used with the keyword FACIITY.

$\begin{array}{ll}\text { ACCEL } & \text { Accelerator } \\ \text { BETAT } & \text { Betatron } \\ \text { CCW } & \text { Cockcroft-Walton accelerator } \\ \text { CHOPF } & \text { Fast chopper } \\ \text { CHOPS } & \text { Slow chopper } \\ \text { CYCLO } & \text { Cyclotron } \\ \text { CYCTM } & \text { Tandem cyclotrons } \\ \text { CYGFF } & \text { Cyclograaff } \\ \text { DYNAM } & \text { Dynamitron } \\ \text { ESTRG } & \text { Electron storage ring } \\ \text { ICTR } & \text { Insulated core transformer accelerator } \\ \text { ISOCY } & \text { Isochronous cyclotron } \\ \text { LINAC } & \text { Linear accelerator } \\ \text { MESON } & \text { Meson facility } \\ \text { MICRT } & \text { Microtron } \\ \text { OLMS } & \text { On-line mass separator } \\ \text { OSCIP } & \text { Pile oscillator } \\ \text { REAC } & \text { Reactor } \\ \text { SELVE } & \text { Velocity selector } \\ \text { SPECC } & \text { Crystal spectrometer } \\ \text { SPECD } & \text { Double mass spectrometer } \\ \text { SPECM } & \text { Mass spectrometer } \\ \text { SYNCH } & \text { Synchrotron } \\ \text { SYNCY } & \text { Synchrocyclotron } \\ \text { VDG } & \text { Van de Graaff } \\ \text { VDGT } & \text { Tandem Van de Graaff }\end{array}$


Dictionary 19: Incident Source codes: used with the keyword INC-SOURCE.

$\begin{array}{ll}\text { A-BE } & \text { Alpha-Beryllium } \\ \text { ARAD } & \text { Annihilation radiation } \\ \text { ATOMI } & \text { Atomic beam source } \\ \text { BRST } & \text { Bremsstrahlung } \\ \text { CF252 } & \text { Spontaneous fission of 252Cf } \\ \text { CM244 } & \text { Spontaneous fission of 244Cm } \\ \text { CM246 } & \text { Spontaneous fission of 246Cm } \\ \text { CM248 } & \text { Spontaneous fission of 248Cm } \\ \text { COMPT } & \text { Compton scattering } \\ \text { D-BE } & \text { Deuteron-Beryllium } \\ \text { D-C12 } & \text { Deuteron-12C } \\ \text { D-C14 } & \text { Deuteron-14C } \\ \text { D-D } & \text { Deuteron-Deuterium } \\ \text { D-LI } & \text { Deuteron-Lithium } \\ \text { D-LI7 } & \text { Deuteron-7Li } \\ \text { D-N15 } & \text { Deuteron-15N } \\ \text { D-T } & \text { Deuteron-Tritium } \\ \text { EVAP } & \text { Evaporation neutrons } \\ \text { EXPLO } & \text { Nuclear explosive device } \\ \text { HARD } & \text { Hardened } \\ \text { KINDT } & \text { Kinematically determined } \\ \text { LAMB } & \text { Lamb-shift source } \\ \text { LASER } & \text { Laser scattering } \\ \text { MPH } & \text { Monoenergetic photons } \\ \text { P-BE } & \text { Proton-Beryllium } \\ \text { P-D } & \text { Proton-Deuterium } \\ \text { P-LI7 } & \text { Proton-7Li } \\ \text { P-T } & \text { Proton-Tritium } \\ \text { PHOTO } & \text { Photo-neutron } \\ \text { POLIS } & \text { Polarized ion source } \\ \text { POLNS } & \text { Polarized neutron source } \\ \text { POLTR } & \text { Polarized target } \\ \text { PU240 } & \text { Spont.fission of 240Pu } \\ \text { QMPH } & \text { Quasi-monoenergetic photons } \\ \text { REAC } & \text { Reactor } \\ \text { SPALL } & \text { Spallation } \\ \text { TAGD } & \text { Electron tagged } \\ \text { THCOL } & \text { Thermal column } \\ \text { THRDT } & \text { Determined by threshold technique } \\ \text { VPH } & \text { Virtual photons } \\ & \end{array}$


Dictionary 20: Additional Result Codes: used with the keyword ADD-RES.

$\begin{array}{ll}\text { A-DIS } & \text { Mass distribution } \\ \text { AMFF } & \begin{array}{l}\text { Angular momentum of fission fragments } \\ \text { ANgular distribution }\end{array} \\ \text { COMP } & \text { Comparison with calculated values } \\ \text { DECAY } & \text { Decay properties investigated } \\ \text { E-DIS } & \text { Energy distribution } \\ \text { G-SPC } & \text { Gamma spectra } \\ \text { LD } & \text { Level density } \\ \text { N-SPEC } & \text { Neutron spectra } \\ \text { P-SPEC } & \text { Proton spectra } \\ \text { POT } & \text { Parameters of nuclear potential } \\ \text { RANGE } & \text { Range of recoils measured } \\ \text { RECIP } & \text { Reciprocal data } \\ \text { STRUC } & \text { Nuclear structure data } \\ \text { THEO } & \text { Theory } \\ \text { TRCS } & \text { Total reaction cross section } \\ \text { TTY-C } & \text { Calculated thick target yield } \\ \text { Z-DIS } & \text { Charge distribution }\end{array}$


Dictionary 21: Method Codes: used with the keyword METHOD.

$\begin{array}{ll}\text { ABSFY } & \text { Absolute fission yield measurement } \\ \text { ACTIV } & \text { Activation } \\ \text { AMS } & \text { Accelerator mass spectrometry } \\ \text { ASEP } & \text { Separation by mass separator } \\ \text { ASSOP } & \text { Associated particle } \\ \text { BCINT } & \text { Beam current integrated } \\ \text { BGCT } & \text { B-? coincidence technique } \\ \text { BSPEC } & \text { B-ray spectrometry } \\ \text { BURN } & \text { Burn-up } \\ \text { CADMB } & \text { Cadmium bath } \\ \text { CHRFL } & \text { Christiansen filter } \\ \text { CHSEP } & \text { Chemical separation } \\ \text { COINC } & \text { Coincidence } \\ \text { DIFFR } & \text { Diffraction } \\ \text { DSCAT } & \text { Double scattering } \\ \text { EDE } & \text { Particle identification by 'E/AE' measurement } \\ \text { EDEG } & \text { Energy degradation by foils } \\ \text { EXTB } & \text { Irradiation with external beam } \\ \text { FISCT } & \text { Absolute fission counting } \\ \text { FLUX } & \text { Neutron flux monitoring } \\ \text { FPGAM } & \text { Direct ?-ray spectrometry } \\ \text { GSPEC } & \gamma \text { - ray spectrometry } \\ \text { HADT } & \text { Heavy atom difference technique } \\ \text { HATOM } & \text { Hot atom method } \\ \text { HEJET } & \text { Collection by He jet } \\ \text { INTB } & \text { Irradiation with internal beam } \\ \text { JET } & \text { Collection by gas jet } \\ \text { LRASY } & \text { Left-right asymmetry } \\ \text { MAGFR } & \text { Magnetic field rotation } \\ \text { MANGB } & \text { Manganese bath } \\ \text { MASSP } & \text { Mass spectrometry } \\ \text { MOMIX } & \text { Mixed monitor } \\ \text { MOSEP } & \text { Separate monitor foil } \\ \text { OLMS } & \text { On-line mass separation } \\ \text { PHD } & \text { Pulse-height discrimination } \\ \text { PLSED } & \text { Pulse die-away } \\ \text { PSD } & \text { Pulse-shape discrimination } \\ \text { RCHEM } & \text { Radiochemical separation } \\ \text { REAC } & \text { Reactivity measurement } \\ \text { REC } & \text { Collection of recoils } \\ \text { REFL } & \text { Total reflection from mirrors } \\ \text { RELFY } & \text { Relative fission yield measurement } \\ \text { RVAL } & \text { R-value measurement } \\ \text { SFLIP } & \text { Spin flip } \\ & \end{array}$


SHELT Shell transmission

SITA

Single target irradiation

SLODT

Slowing-down time

STATD

Statistically determined

STTA

Stacked target irradiation

TOF

Time-of-flight 
Dictionary 22: Detector Codes: used with the keyword DETECTOR.

$\begin{array}{ll}\text { BF3 } & \text { BF3 neutron detector } \\ \text { BGO } & \text { Bismuth-germanate crystal detector } \\ \text { BPAIR } & \text { Electron-pair spectrometer } \\ \text { CEREN } & \text { Cerenkov detector } \\ \text { COIN } & \text { Coincidence counter arrangement } \\ \text { CSICR } & \text { Cesium-Iodide crystal } \\ \text { D4PI } & \text { 4p detector } \\ \text { FISCH } & \text { Fission chamber } \\ \text { GE-IN } & \text { Germanium intrinsic detector } \\ \text { GELI } & \text { Ge(Li) detector } \\ \text { GEMUC } & \text { Geiger-Mueller counter } \\ \text { GLASD } & \text { Glass detector } \\ \text { HE3SP } & \text { 3He spectrometer } \\ \text { HORBU } & \text { Hornyak button detector } \\ \text { HPGE } & \text { Hyperpure Germanium detector } \\ \text { IOCH } & \text { Ionization chamber } \\ \text { LONGC } & \text { Long counter } \\ \text { MAGSP } & \text { Magnetic spectrometer } \\ \text { MOXR } & \text { Moxon-Rae detector } \\ \text { MTANK } & \text { Moderating tank detector } \\ \text { MWPC } & \text { Position sensitive multi-wire proportional counter } \\ \text { NAICR } & \text { NaI(Tl) crystal } \\ \text { PLATE } & \text { Nuclear plates } \\ \text { PROPC } & \text { Proportional counter } \\ \text { PSSCN } & \text { Position sensitive scintillator } \\ \text { PSSSD } & \text { Position sensitive solid state detector } \\ \text { SCIN } & \text { Scintillation detector } \\ \text { SILI } & \text { Si(Li) detector } \\ \text { SOLST } & \text { Solid-state detector } \\ \text { STANK } & \text { Scintillator tank } \\ \text { SWPC } & \text { Position sensitive single-wire proportional counter } \\ \text { TELES } & \text { Counter telescope } \\ \text { THRES } & \text { Threshold detector } \\ \text { TRD } & \text { Track detector } \\ & \end{array}$


Dictionary 23: Analysis Codes: used under the keyword ANALYSIS.

4PIlA 4p times differential cross section at one angle

AREA Area analysis

CORAB Correction for isotopic abundance

DECAY Decay curve analysis

DIFFR Difference spectrum

DTBAL Detailed balance

INTAD Integration of angular distribution

INTED Integration of energy distribution

LEAST Least-structure method

MLA Multilevel analysis

PHDIF Photon difference

PLA Penfold-Leiss method

REDUC Reduction method

REGUL Regularization method

RFN R-function formalism

SHAPE Shape analysis

SLA Single level analysis

THIES Thies's method

UNFLD Unfolding procedure

WSP Woods-Saxon potential 
Dictionary 24: Data Headings: used at the beginning of the COMMON and DATA fields to indicate the significance of the variable given; also used under the keywords ASSUMED, MONITOR, HALF-LIFE, MISC, and ERR-ANALYS as links to the data field.

The codes given in this dictionary may be followed by one of the following suffixes.

$-1,-2$, etc. $1^{\text {st }}, 2^{\text {nd }}$, etc., value, when more than one defined

-APRX value is approximate

$-\mathrm{CM}$ value is in center-of-mass (quantities without this suffix are in the laboratory system

-DN value for denominator of a reaction ratio

-ERR uncertainty on value

-MIN minimum value

-MAX maximum value

-MEAN mean value

-NM value for numerator of a reaction ratio

-NRM value at which data is normalized

-RSL resolution of value

$\begin{array}{ll}\text { ANAL-STEP } & \text { Analysis energy step } \\ \text { ANG } & \text { Angle } \\ \text { ASSUM } & \text { Assumed value, defined under ASSUMED } \\ \text { COS } & \text { Cosine of angle } \\ \text { DATA } & \text { Value of quantity Specified under REACTION } \\ \text { DECAY-FLAG } & \text { Decay flag. link to information under DECAY-DATA } \\ \text { E } & \text { Energy of outgoing particle } \\ \text { E-DGD } & \text { Degradation in secondary particle energy vs. incident energy } \\ \text { E-EXC } & \text { Excitation energy } \\ \text { E-GAIN } & \text { Gain in secondary particle energy vs. incident energy } \\ \text { E-LVL } & \text { Level energy } \\ \text { E-LVL-FIN } & \text { Final level of ? transition } \\ \text { E-LVL-INI } & \text { Initial level of ? transition } \\ \text { ELEMENT } & \text { Atomic number of element } \\ \text { EMS } & \text { Effective mass squared } \\ \text { EN } & \text { Energy of incident projectile } \\ \text { EN-DUMMY } & \text { Dummy incident projectile energy, for broad spectrum } \\ \text { EN-RES } & \text { Resonance energy } \\ \text { EN-RSL-FW } & \text { Incident projectile energy resolution (FWHM) } \\ \text { EN-RSL-HW } & \text { Incident projectile energy resolution (?? FWHM) } \\ \text { ERR } & \text { Systematic uncertainty, defined under ERR-ANALYS } \\ \text { ERR-S } & \text { Statistical uncertainty (1 s) } \\ \text { ERR-T } & \text { Total uncertainty (1 s) } \\ \text { FLAG } & \text { Flag, link to information under FLAG } \\ \text { HL } & \text { Half-life of nuclide specified } \\ \text { ISOMER } & \text { Isomeric state for nuclide given } \\ \text { KT } & \text { Spectrum temperature } \\ \text { LVL-FLAG } & \text { Level flag, link to information under LEVEL-PROP } \\ \text { LVL-NUMB } & \text { Level number } \\ & \end{array}$




$\begin{array}{ll}\text { MASS } & \text { Atomic mass of nuclide } \\ \text { MASS-RATIO } & \text { Ratio of atomic masses of fission fragments } \\ \text { MISC } & \text { Miscellaneous information, defined under MISC-COL } \\ \text { MOM } & \text { Linear momentum of incident projectile } \\ \text { MOM-SEC } & \text { Linear momentum of outgoing particle } \\ \text { MOMENTUM L } & \text { Angular momentum ( } l \text { ) of resonance } \\ \text { MONIT } & \text { Normalization value, for reaction given under MONITOR } \\ \text { MSS-T } & \text { Transverse mass of outgoing projectile (relativistic data) } \\ \text { MSS-TK } & \text { Transverse mass minus rest mass of outgoing projectile (relativistic data) } \\ \text { MU-ADLER } & \mu \text { (for Adler-Adler resonance parameters) } \\ \text { N-OUT } & \text { Number of emitted neutrons, for variable number of nucleons in reaction } \\ \text { NUMBER } & \text { Fitting coefficient number } \\ \text { P-OUT } & \text { Number of emitted protons, for variable number of nucleons in reaction } \\ \text { PARITY } & \text { Parity (p) of resonance } \\ \text { POL-BM } & \text { Beam polarization } \\ \text { POL-TR } & \text { Target polarization } \\ \text { POLAR } & \text { Polarity } \\ \text { Q-VAL } & \text { Q-value } \\ \text { RAP } & \text { Rapidity (relativistic data, function of (energy+mom(?))/(energy-mom(?)) } \\ \text { RAP-PS } & \text { Pseudo rapidity (relativistic data, function of (mon+mom(?))/(mon-mom(?)) } \\ \text { SPIN J } & \text { Spin (J) of resonance } \\ \text { STAT-W G } & \text { Statistical-weight factor (g) } \\ \text { TEMP } & \text { Sample temperature } \\ \text { THICKNESS } & \text { Sample thickness } \\ & \end{array}$

Dictionary 30: Process Codes: used in REACTION subfield 3, and simarly under ASSUMED and MONITOR.

$\begin{array}{ll}\text { ABS } & \text { Absorption } \\ \text { EL } & \text { Elastic scattering } \\ \text { F } & \text { Fission } \\ \text { INL } & \text { Inelastic scattering } \\ \text { NON } & \text { Nonelastic (= total minus elastic) } \\ \text { PAI } & \text { Pair production (for photonuclear reactions) } \\ \text { SCT } & \text { Total scattering (elastic }+ \text { inelastic) } \\ \text { THS } & \text { Thermal neutron scattering } \\ \text { TOT } & \text { Total } \\ \text { X } & \text { Process unspecified } \\ \text { XN } & \text { Variable number of emitted neutrons } \\ \text { YP } & \text { Variable number of emitted protons }\end{array}$


Dictionary 33: Particle Codes: used in REACTION quantity subfields 2, 3, 7, and simarly under ASSUMED and MONTTOR. Also used under the keywords DECAY-DATA, DECAY-MON, PART-DET and RAD-DET, and as the second field under the keywords EN-SEC, EMS-SEC, and MOM-SEC.

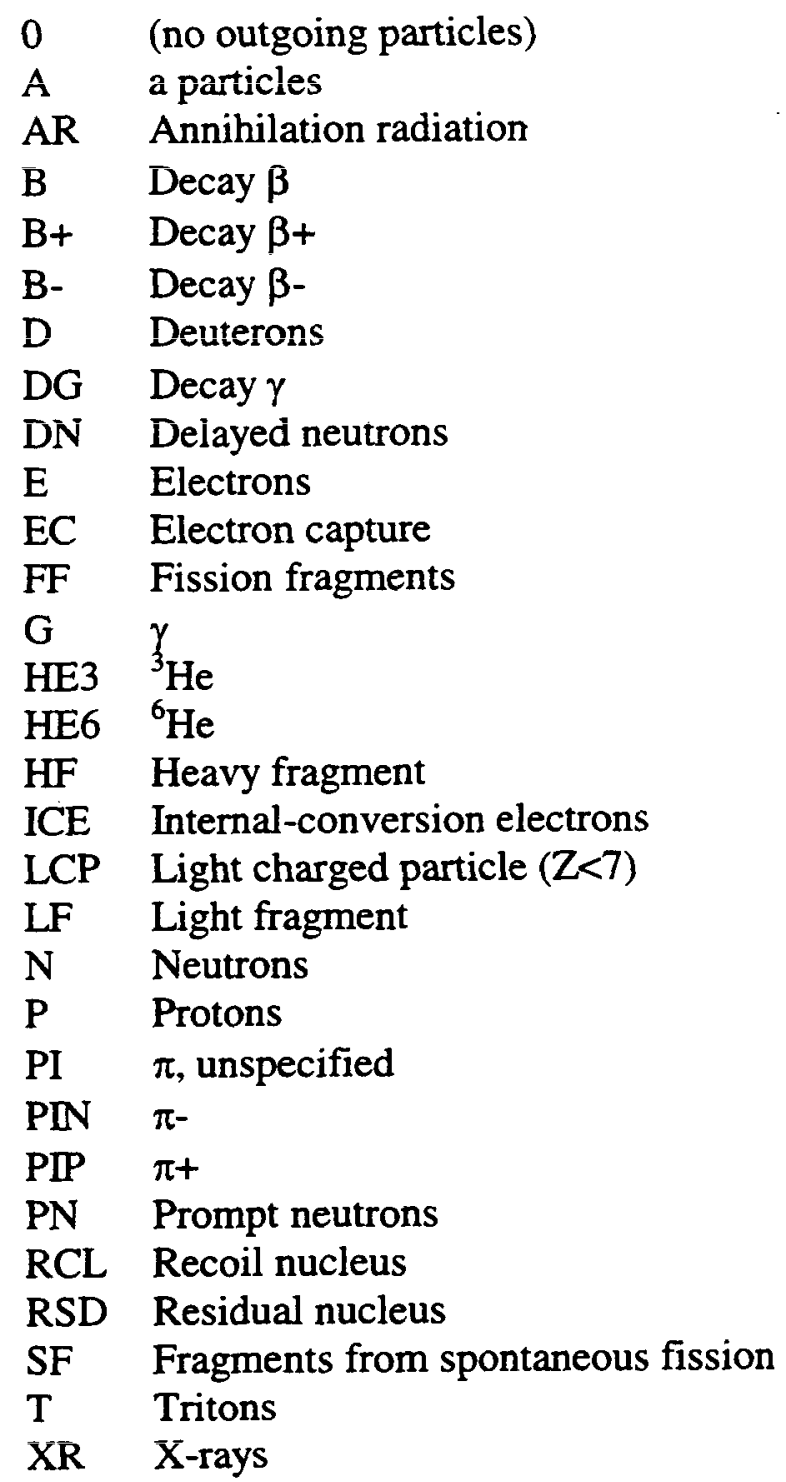


Dictionary 34: Modifier Codes: used in REACTION the $4^{\text {th }}$ quantity subfield (REACTION SF8), and similarly, under ASSUMED and MONITOR.
(A) uncertain if corrected for natural isotopic abundance
$1 \mathrm{~K} 2$ form: $\mathrm{k}^{2} \mathrm{~d} \sigma / \mathrm{d} \Omega=\Sigma\left(\mathrm{a}(\mathrm{L})^{*} \mathrm{p}(\mathrm{L})\right)$
2AG times $2 *$ isotopic abundance and statistical weight factor
$2 \mathrm{G}$ times $2 *$ staistical weight factor
$2 \mathrm{~L} 2$ form: $d \sigma / d \Omega=1 / 2 \Sigma(2 \mathrm{~L}+1)^{*} \mathrm{a}(\mathrm{L}) * \mathrm{p}(\mathrm{L})$
2MT times $2 \mathrm{p} *$ transverse secondary mass
$2 \mathrm{PT}$ times $2 \mathrm{p}^{*}$ transverse secondary momentum
4 AG times $4 *$ isotopic abundance and statistical weight factor
4PI times $4 \pi$
A times natural isotopic abundance
AA Adler-Adler formalism
AG times isotopic abundance and statistical weight factor
AL1 Associated Legendre polynomials of the first kind
ANA analyzing power
ASY asymmetry of polarization of outgoing particles
AV average
AYY spin-correlation function, spins normal to scattering plane
BRA Bremsstrahlung spectrum average
BRS average over part of Bremsstrahlung spectrum
COS Cosine coefficients
CS2 form: $a_{0}+a_{1} * \sin ^{2}+a_{2} * \sin ^{2} * \cos +a_{3} * \sin 2 * \cos ^{2}$
EPI epi-thermal neutron spectrum average
FCT times a factor (see text)
FIS fission spectrum average
FST fast reactor neutron spectrum average
G times statistical weight factor
LAP form: $4 \pi \mathrm{ds} / \mathrm{d} \Omega=\Sigma(2 \mathrm{~L}+1) * \mathrm{a}(\mathrm{L}) * \mathrm{p}(\mathrm{L})$
LEG Legendre coefficients
LIM given for a limited energy range
MSC approximate definition only (see text)
MXW Maxwellian average
PP Incident projectile parallel/perpendicular to reaction plane
RAT ratio
RAW raw data (see text)
REL relative data
RES at peak of resonance
RM Reich-Moore formalism
RMT R-matrix formalism
RNV non-1/v part
RS times $4 \pi / \sigma$
RS0 $(\mathrm{d} \sigma / \mathrm{d} \Omega) /\left(\mathrm{d} \sigma / \mathrm{d} \Omega\right.$ at $\left.0^{\circ}\right)=\Sigma \mathrm{a}(\mathrm{L})^{*} \mathrm{p}(\mathrm{L})$
RSD relative to $90^{\circ}$ data
RSL form: $(4 \mathrm{p} / \sigma)^{*}(\mathrm{~d} \sigma / \mathrm{d} \Omega)=\Sigma(2 \mathrm{~L}+1)^{*} \mathrm{a}(\mathrm{L})^{*} \mathrm{p}(\mathrm{L})$ 


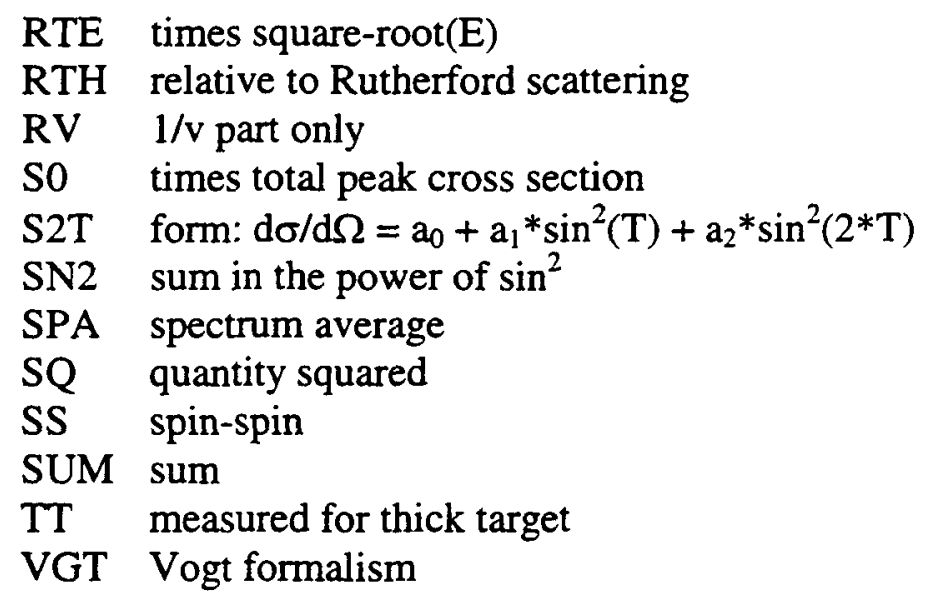

Dictionary 35: Data Type Codes: used in REACTION subfield 9.

$\begin{array}{ll}\text { CALC } & \text { Calculated data } \\ \text { DERIV } & \text { Derived data } \\ \text { EVAL } & \text { Evaluated data } \\ \text { EXP } & \text { Experimental data } \\ \text { RECOM } & \text { Recommended data }\end{array}$


Dictionary 36: Quantity Codes: used for quantity (REACTION subfields 5-7), and simarlarly under ASSUMED and MONITOR. They may be combined with modifer codes from Dictionary 34 to form the complete quantity string. The code $*$ in the $3^{\text {rd }}$ field (SF7) signifies that any particle code from Dictionary 33 given in place of the character.

The following branch codes may appear at the beginning of the string:

CUM cumulative

(CUM) uncertain if reaction is cumulative

M+ including decay from metastable state

M- $\quad$ excluding decay from metastable state

(M) uncertain if decay from metastable state included.

SEQ given for reaction sequence specified

UND the reaction is undefined, only the sum of outgoing nucleons is known.

(DEF) Compiler is uncertain whether the reaction is defined.

\begin{tabular}{|c|c|}
\hline ,AG,,AA & Adler-Adler symmetry coefficient \\
\hline AH,,AA & Adler-Adler asymmetry coefficient \\
\hline ,AKE & Average kinetic energy of outgoing particle \\
\hline ,AKE/DA, * & Avgerage kinetic energy of fission fragment at given angle \\
\hline ,ALF & Capture-to-fission cross section ratio \\
\hline ,AMP & Scattering amplitude \\
\hline ,AP & Most probable mass of fission products \\
\hline ,AP,* & Most probable mass of fragment specified \\
\hline ,ARE & Resonance area \\
\hline ,COR & Angular correlation \\
\hline ,COR, $* / *$ & Angular correlation between particles specified \\
\hline ,COR,*/*/* & Angular correlation between particles specified \\
\hline ,D & Average level spacing \\
\hline ,DA & Differential cross section with respect to angle \\
\hline ,DA,* & Differential cross section with respect to angle for particle specified \\
\hline ,DA/DA & Double differential cross section $\mathrm{d}^{2} \sigma / \mathrm{d} \Omega / \mathrm{d} \Omega$ \\
\hline ,DA/DA, $* * *$ & Double diff. cross section $d^{2} \sigma / d \Omega\left({ }^{*} 1\right) / d \Omega\left({ }^{*} 2\right)$ \\
\hline ,DA/DA/DE & Triple diff.cross section $\mathrm{d}^{3} \sigma / \mathrm{dA} / \mathrm{dO} / \mathrm{dE}$ \\
\hline ,DA/DA/DE, $* / * / *$ & Triple diff.cross section $\mathrm{d}^{3} \sigma / \mathrm{d} \Omega\left({ }^{*} 1\right) / \mathrm{dO}\left({ }^{*} 2\right) / \mathrm{dE}\left({ }^{*} 3\right)$ \\
\hline ,DA/DE & Double diff.cross section $\mathrm{d}^{2} \sigma / \mathrm{d} \Omega / \mathrm{dE}$ \\
\hline ,DA/DE,* & Double diff.cross section $d^{2} \sigma / d \Omega / d E$ of particle specified \\
\hline ,DA/DE/DE, $* / * / *$ & Triple diff.cross section $\mathrm{d}^{3} \sigma / \mathrm{d} \Omega\left({ }^{*} 1\right) / \mathrm{dE}\left({ }^{*} 2\right) / \mathrm{dE}(* 3)$ \\
\hline ,DA/KE,* & Kinetic energy of fission fragment specified with respect to angle \\
\hline ,DAVTYA,P & Differential cross section with respect to Treiman-Yang angle \\
\hline ,DE & Energy spectrum of outgoing particles \\
\hline ,DE,* & Energy spectrum of particle specified \\
\hline ,ECO & Energy correlation \\
\hline ,EMC & Effective mass correlation \\
\hline ,EN & Resonance energy \\
\hline ,ETA & Neutron yield $(\eta)$ \\
\hline ,ETA/NU & $\eta / v$ \\
\hline
\end{tabular}




\begin{tabular}{|c|c|}
\hline ,FM/DA & Angular distribution, of $1 \mathrm{st}$ kind \\
\hline ,FM2/DA & Spin-polarization probability of 1st kind \\
\hline ,INT & Cross-section integral over incident energy \\
\hline ,J & Spin $J$ \\
\hline ,KE,* & Kinetic energy of fission fragments specified \\
\hline ,KER & Kerma factor \\
\hline ,L & Momentum $l$ \\
\hline ,LDP & Level density parameter \\
\hline ,MCO & Linear momentum correlation \\
\hline ,MLT & Multiplicity of outgoing particle \\
\hline ,MLT,* & Multiplicity of particle specified \\
\hline ,NU & Total neutron yield $(\bar{v})$ \\
\hline ,PHS & Relative phase \\
\hline PN & Delayed neutron emission probability \\
\hline ,POL & Spin-polarization probability \\
\hline ,POL,* & Spin-polarization probability of particle specified \\
\hline ,POL/DA & Spin-polarization probability $\mathrm{d} \sigma / \mathrm{d} \Omega$ \\
\hline ,POLDA,* & Diff. spin-polarization probability $d \sigma / d \Omega$ of particle specified \\
\hline ,PTY & Parity \\
\hline ,PY & Product yield \\
\hline RAD & Scattering radius \\
\hline ,RI & Resonance integral \\
\hline ,SCO & Spin-cut-off factor \\
\hline ,SGV & Reaction rate (s*velocity) \\
\hline SIG & Cross section \\
\hline ,SIG,* & Cross section for production of particle specified \\
\hline ,SIG/RAT & Cross section ratio \\
\hline ,SIG/TMP & Temperature-dependent cross section \\
\hline ,SPC & Gamma spectrum \\
\hline ,SPC/DA & Gamma spectrum as function of angle \\
\hline ,STF & Strength function \\
\hline ,SWG & Statistical weight factor $\mathrm{g}$ \\
\hline ,TEM & Nuclear temperature \\
\hline ,TTT & Thick-target yield per unit time \\
\hline ,TTT/DA & Thick-target yield per unit time $\mathrm{d} Y / \mathrm{d} \Omega$ \\
\hline ,TTY & Thick-target yield \\
\hline ,TTY/DA & Differential thick target yield $\mathrm{d} Y / \mathrm{d} \Omega$ \\
\hline ,TTY/DA/DE & Differential thick target yield $\mathrm{dY} / \mathrm{d} \Omega / \mathrm{dE}$ \\
\hline ,TTY/DE & Differential thick target yield $\mathrm{dY} / \mathrm{dE}$ \\
\hline ,WID & Resonance width, $\Gamma$ \\
\hline ,WID/RED & Reduced width, $\Gamma_{0}$ \\
\hline ,ZP & Most probable charge of fission products \\
\hline $1, \mathrm{WID}$ & Resonance width for channel 1 \\
\hline 2,DE & Energy spectrum of 2nd secondary particle \\
\hline $2, \mathrm{WID}$ & Resonance width for channel 2 \\
\hline 3,WID & Resonance width for channel 3 \\
\hline
\end{tabular}




\begin{tabular}{|c|c|}
\hline $4, W D$ & Resonance width for channel 4 \\
\hline BA,AMP & Bound-atom scattering amplitude \\
\hline BA,SIG & Bound-atom cross section \\
\hline $\mathrm{BA} / \mathrm{COH}, \mathrm{AMP}$ & Bound-atom coherent scattering amplitude \\
\hline BA/PAR,AMP & Partial bound-atom scattering amplitude \\
\hline $\mathrm{BIN}, \mathrm{AKE}, *$ & Average kinetic energy of fission fragment specified \\
\hline $\mathrm{BIN}, \mathrm{AP}, *$ & Most prob. mass of fission fragment specified in binary fission \\
\hline BIN,SIG & Binary fission cross section \\
\hline BIN/TER,DA/RAT,* & Binary/ternary differential dist. $\mathrm{d} \sigma / \mathrm{d} \Omega$ of fission fragment specified \\
\hline BIN/TER,SIG/RAT & Binary/ternary cross section ratio \\
\hline CHG,FY & Total element yield of fission products \\
\hline CHG,FY/DE & Total element fission yield, differential dY/d(fragment energy) \\
\hline CHN,FY & Total chain yield of fission products \\
\hline CHN,FY/DE & Total chain fission yield, differential dY/d(fragment energy) \\
\hline $\mathrm{CN}, \mathrm{DA}$ & Differential cross section $\mathrm{d} \sigma / \mathrm{d} \Omega$, compound nucleus contribution \\
\hline CN,FY & Fission-product yield, compound nucleus contribution \\
\hline $\mathrm{CN}, \mathrm{NU}$ & $? \mathrm{v}$, compound nucleus contribution \\
\hline CN,PY & Product yield, compound nucleus contribution \\
\hline CN,SIG & Cross section, compound nucleus contribution \\
\hline CN/PAR,SIG & Partial cross section, compound nucleus contribution \\
\hline $\mathrm{COH}, \mathrm{AMP}$ & Coherent scattering amplitude \\
\hline $\mathrm{COH}, \mathrm{SIG}$ & Coherent cross section \\
\hline CUM,FY & Cumulative fission-product yield \\
\hline CUM,FY/RAT & Cummulative fission-product yield isomeric ratio \\
\hline CUM/TER,FY & Cumulative fission product yield for ternary fission \\
\hline DI,DA & Differential c/s d $\sigma / \mathrm{d} \Omega$, direct interaction contribution \\
\hline DI,DA/DE & Double diff. $c / \mathrm{s} \mathrm{d}^{2} \sigma / \mathrm{d} \Omega / \mathrm{dE}$, direct interaction contribution \\
\hline DI,SIG & Cross section, direct interaction contribution \\
\hline DI/PAR,DA & Partial diff. $\mathrm{c} / \mathrm{s} \mathrm{d} \sigma / \mathrm{d} \Omega$, direct interaction contribution \\
\hline DI/PAR,DA/DE & Partial double diff. $c / s \mathrm{~d} 2 / \mathrm{dA} / \mathrm{dE}$, direct interaction contribution \\
\hline DI/PAR,SIG & Partial cross section, direct interaction contribution \\
\hline $\mathrm{DL}, \mathrm{AKE}, *$ & Average kinetic energy of delayed particle specified \\
\hline DL,DE,* & Delayed energy spectrum of particle specified \\
\hline DL,NU & Delayed neutron yield \\
\hline DL,SIG,* & Delayed emission cross section of particle specified \\
\hline $\mathrm{DL}, \mathrm{SPC}$ & Intensity of delayed gammas \\
\hline DL/PAR,AKE,* & Average kinetic energy for specified delayed particle group \\
\hline DLSPAR,DE,* & Energy spectrum for specific delayed particle group \\
\hline DLPAR,NU & Partial yield of delayed neutrons \\
\hline DLPAR,SIG, $*$ & Partial delayed emission cross section for particle specified \\
\hline EM,DA & Particle emission angular distribution \\
\hline $\mathrm{EM}, \mathrm{DA} / \mathrm{DE}$ & Double differential emission cross section, $\mathrm{d} \sigma / \mathrm{d} \Omega / \mathrm{dE}$ \\
\hline EM,DE & Particle emission energy spectrum \\
\hline EM,SIG & Emission cross section \\
\hline EM/PAR,DA & Particle emission partial differential cross section, $\mathrm{d} \sigma / \mathrm{d} \Omega$ \\
\hline EM/PAR,SIG & Partial emission cross section \\
\hline
\end{tabular}


EP,DA

EP,SIG

EP/PAR,INT

EP/PAR,SIG

FA,SIG

FA/COH,SIG

FA/INC,SIG

FA/PAR,AMP

HEN,SIG

INC,AMP

INC,SIG

IND,FY

IND,FY,*

IND,FY/DE

IND,FY/RA

IND/TER,FY

LEN,SIG

MP,SIG

PAR,ARE

PAR,COR

PAR,DA

PAR,DA,*

PAR,DA/DA

PAR,DA/DA, $* / *$

PAR,DA/DA/DE, $* / * / *$

PAR,DA/DE

PAR,FM/DA

PAR,WNT/DA,*

PAR,MLT,*

PAR,NU

PAR,POL/DA

PAR,SIG

PAR,SIG,*

PAR,STF

PAR,TTY

PAR,TTY,*

PAR,WID

POT,RAD

POT,SIG

PR,AKE,N

$\mathrm{PR}, \mathrm{COR}, \mathrm{N} / \mathrm{N}$

PR,COR/DE,N/FF

PR,DA,N

PR,DA/DE,N

PR,DE,N

PR,NU
Partial differential cross section $\mathrm{d} \sigma / \mathrm{d} \Omega$ for electric polarity

Cross section for electric polarity

Cross section integral over incident energy for electric polarity

Partial cross section for electric polarity

Free-atom cross section

Free-atom coherent scattering cross section

Free-atom incoherent scattering cross section

Partial free-atom scattering amplitude

'High-energy' component of cross section

Incoherent scattering amplitude

Incoherent scattering cross section

Independent fission yield

Independent yield of particle specified from prompt fission prod.

Differential independent fission yield $\mathrm{dY} / \mathrm{d}$ (fragment energy)

Independent fission yield ratio

Independent fission yield for ternary fission

'Low-energy' component of cross section

Cross section for magnetic polarity given

Partial resonance area

Partial reaction, angular correlation

Partial differential cross section, $\mathrm{d} \sigma / \mathrm{d} \Omega$

Partial differential cross section, $d \sigma / d \Omega$, of particle specified

Partial double differential cross section $\mathrm{d}^{2} \sigma / \mathrm{d} \Omega / \mathrm{d} \Omega$

Partial double differential cross section $\mathrm{d}^{2} \sigma / \mathrm{d} \Omega\left({ }^{*} 1\right) / \mathrm{d} \Omega\left({ }^{*} 2\right)$

Partial triple differential cross section $\mathrm{d}^{3} \sigma / \mathrm{d} \Omega(* 1) / \mathrm{d} \Omega(* 2) / \mathrm{dE}(* 3)$

Partial double differential cross section $\mathrm{d} \sigma / \mathrm{d} \Omega$

Partial differential cross section, d $\sigma / \mathrm{d} \Omega$, for polynomial of 1 st kind

Integral over incident en. of partial diff. $c / s, d \sigma / d \Omega$, of particle specified

Partial multiplicity of particle specified

Partial yield of neutrons $\bar{v}$

Differential spin-polarization probability for partial reaction

Partial cross section

Partial cross section for particle specified

Partial strength function

Partial thick target yield

Partial thick target yield for particle specified

Partial width

Potential scattering radius

Potential scattering cross section

Average kinetic energy of prompt neutrons

Angular correlation of prompt neutrons

Angle-energy correlation of prompt neutrons with fission fragments

Differential cross section, $d \sigma / d \Omega$ of prompt neutrons

Double differential cross section of prompt neutrons, $\mathrm{d} 2 \sigma / \mathrm{d} \Omega / \mathrm{dE}$

Energy spectrum of prompt fission neutrons

Prompt neutron yield $(\bar{v})$ 


\begin{tabular}{|c|c|}
\hline $\begin{array}{l}\text { PR,SIG } \\
\text { PR,SPC }\end{array}$ & $\begin{array}{l}\text { Prompt cross section } \\
\text { Intensity of prompt gammas }\end{array}$ \\
\hline PR/PAR,NU & Partial prompt neutron yield $(\bar{v})$ \\
\hline PR/TER,DA,N & Ang.dist of prompt neutrons from ternary fission \\
\hline PR/TER,NU & Prompt $\bar{v}$ for ternary fission \\
\hline PR/TER,NU/DE,A & Prompt $\bar{v}$ for ternary fission as a function of alpha energy \\
\hline PR/TER,SPC & Prompt gamma spectrum from ternary fission \\
\hline PRE,AKE,* & Average kinetic energy of fragment specified \\
\hline PRE,AP,* & Most probable mass, pre-neutron-emission, of fragment specified \\
\hline PRE,DA,* & Differential cross section, $\mathrm{d} \sigma / \mathrm{d} \Omega$, of primary fragments specified \\
\hline PRE,DA/KE, ${ }^{*}$ & Kinetic energy distribribution, $\mathrm{d} \sigma / \mathrm{d} \Omega$, of primary fragment specified \\
\hline PRE,DE, * & Energy spectrum of primary fragments specified \\
\hline PRE,FY & Primary fission yield \\
\hline PRE,FY/DE & Primary fission yield $d Y / d($ kinetic energy) \\
\hline PRE,KE,* & Kinetic energy of primary fragments specified \\
\hline PRE/BIN,FY & Primary fission yield, binary fission \\
\hline PRE/TER,FY & Primary fission yield, ternary fission \\
\hline SEC,AKE,FF & Average kinetic energy of post-neutron-emission fragment \\
\hline SEC,AP,* & Most probable mass of post-neutron-emission fragment specified \\
\hline SEC,FY & Post-neutron-emission fission yield \\
\hline SEC/CHN,FY & Pre-delayed-neutron chain yield \\
\hline SEC/CHN,FY/DE & Pre-delayed-neutron chain yield dY/d(kinetic energy) \\
\hline TER,AKE,* & Average kinetic energy of particle specified, ternary fission \\
\hline TER,AP & Most probable mass of fragment, ternary fission \\
\hline TER,AP,* & Most prob. mass of ternary fission fragment specified \\
\hline TER,COR, $* / *$ & Angular correlation of particle $* 1 \&$ particle $* 2$, ternary fission \\
\hline TER,DA,* & Differential cross section, d $\sigma / d \Omega$, of particle specified, ternary fission \\
\hline TER,DA/DE,* & $\begin{array}{l}\text { Double-differential cross sect. } d^{2} \sigma / d \Omega / d E \text { of particle spec., ternary } \\
\text { fission }\end{array}$ \\
\hline TER,DA/KE,* & $\begin{array}{l}\text { Kinetic energy distribution, } \mathrm{dE}_{\mathrm{kin}} / \mathrm{d} \Omega \text {, of particle specified, ternary } \\
\text { fission }\end{array}$ \\
\hline TER,DE,* & Energy spectrum of particle specified, ternary fission \\
\hline TER,FY & Fission yield, ternary fission \\
\hline TER,FY,* & Fission yield of fragment specified, temary fission \\
\hline TER,SIG & Cross section, ternary fission \\
\hline TER,SIG,* & Cross section of particle specified, ternary fission \\
\hline TER,ZP & Most probable charge of fragment, ternary fission \\
\hline TER/BIN,SIG/RAT & Ternary/binary fission cross section ratio \\
\hline
\end{tabular}

Dictionary 37: Result Codes: used with the keyword RESULT.

$\begin{array}{ll}\text { CAPTA } & \mathrm{g} \Gamma_{\mathrm{n}} \Gamma \gamma / \Gamma \\ \text { FRCUM } & \text { Fractional cumulative yield } \\ \text { FRIND } & \text { Fractional independent yield } \\ \text { RVAL } & \text { R-value }\end{array}$


EXFOR Basics

\section{Appendix E}

\section{Example of an EXFOR Entry}

Attached is an example of a complete entry in the EXFOR format.

E.1 


\section{$\tau^{*} \exists$}

so!seg XOAX马 


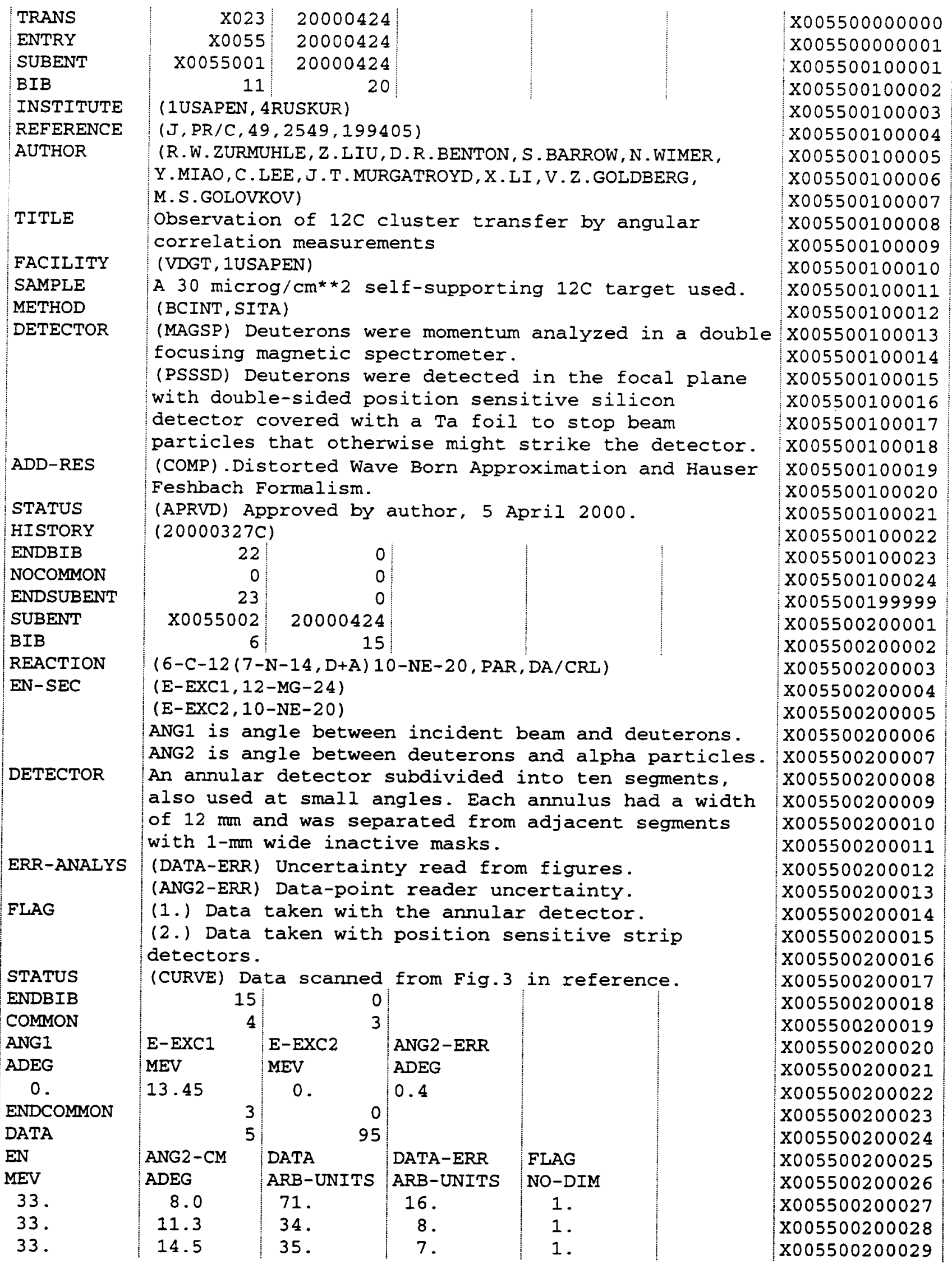




\begin{tabular}{|c|c|c|c|c|c|}
\hline $\begin{array}{l}33 . \\
33 .\end{array}$ & $\begin{array}{l}16.7 \\
17.3\end{array}$ & $\begin{array}{l}30 . \\
26 .\end{array}$ & $\begin{array}{l}4 . \\
5 .\end{array}$ & $\begin{array}{l}2 . \\
1 .\end{array}$ & $\begin{array}{l}x 005500200030 \\
x 005500200031\end{array}$ \\
\hline$\ldots$ & $\ldots$ & $\ldots$ & & & \\
\hline 33. & 108.0 & 11.0 & 4.0 & 2 . & $x 005500200075$ \\
\hline 42 . & 11.4 & 28.0 & 4. & 1. & $x 005500200076$ \\
\hline 42 . & 15.9 & 17.7 & 2 . & 1. & X005500200077 \\
\hline 42 . & 17.7 & 18.7 & 2.5 & 2 . & $x 005500200078$ \\
\hline 42 . & 19.9 & 16.7 & 1.8 & 1. & $x 005500200079$ \\
\hline 42 . & 112.7 & 5.9 & 1.5 & 2. & $x 005500200122$ \\
\hline ENDDATA & 97 & 0 & & & $x 005500200123$ \\
\hline ENDSUBENT & 122 & 0 & & & X005500299999 \\
\hline SUBENT & $x 0055003$ & 20000424 & & & $\mathrm{X} 005500300001$ \\
\hline$B I B$ & 3 & 3 & & & $x 005500300002$ \\
\hline REACTION & $(6-c-12(7-1)$ & $N-14, D+A) 10$ & $-\mathrm{NE}-20, \mathrm{PAR}$, & $D A, D)$ & $\times 005500300003$ \\
\hline ERR-ANALYS & (DATA-ERR) & Relative u & uncertainty & given. & $x 005500300004$ \\
\hline STATUS & Data taken & from Table & III in ref & erence. & $\mathrm{x} 005500300005$ \\
\hline ENDBIB & 3 & & & & $\times 005500300006$ \\
\hline COMMON & 1 & 3 & & & $\times 005500300007$ \\
\hline EN & $E-E X C$ & & & & $\mathrm{X} 005500300008$ \\
\hline MEV & MEV & & & & $x 005500300009$ \\
\hline 33. & 13.45 & & & & $x 005500300010$ \\
\hline ENDCOMMON & 3 & & & & $x 005500300011$ \\
\hline DATA & 3 & 5 & & & $x 005500300012$ \\
\hline ANG & DATA & DATA-ERR & & & $\times 005500300013$ \\
\hline ADEG & $\mathrm{MB} / \mathrm{SR}$ & PER-CENT & & & $\mathrm{X} 005500300014$ \\
\hline 6.01 & 0.39 & 10 & & & $x 005500300015$ \\
\hline 12.3 & 0.40 & 10. & & & $\times 005500300016$ \\
\hline 18.3 & 0.27 & 11. & & & X005500300017 \\
\hline 30.4 & 0.28 & 11. & & & $\mathrm{x} 005500300018$ \\
\hline 36.5 & 0.27 & 11. & & & $x 005500300019$ \\
\hline ENDDATA & 7 & & & & $x 005500300020$ \\
\hline ENDSUBENT & 19 & & & & $\mathrm{x} 005500399999$ \\
\hline SUBENT & $x 0055004$ & 20000424 & & & $\mathrm{X} 005500400001$ \\
\hline BIB & 3 & 3 & & & $\mathrm{x} 005500400002$ \\
\hline REACTION & $(6-C-12(7-1)$ & $N-14, D+A) 10$ & -NE-20, PAR, & SIG) & $x 005500400003$ \\
\hline ANALYSIS & (INTAD) & & & & $\times 005500400004$ \\
\hline ERR-ANALYS & (DATA-ERR) & Absolute u & incertainty & given. & $x 005500400005$ \\
\hline STATUS & (DEP, X0055 & 003) Data $t$ & Eaken from t & ext in reference. & $\mathrm{x} 005500400006$ \\
\hline ENDBIB & 3 & & & & X005500400007 \\
\hline NOCOMMON & 0 & 0 & & & $x 005500400008$ \\
\hline DATA & 3 & 1 & & & $x 005500400009$ \\
\hline EN & $E-L V L$ & DATA & DATA-ERR & & $\mathrm{x} 005500400010$ \\
\hline MEV & MEV & MB & MB & & $x 005500400011$ \\
\hline 33 . & 13.45 & 3.6 & 0.5 & & $\mathrm{X} 005500400012$ \\
\hline ENDDATA & 3 & & & & $x 005500400013$ \\
\hline ENDSUBENT & 12 & & & & X005500499999 \\
\hline ENDENTRY & 3 & & & & X005599999999 \\
\hline ENDTRANS & 1 & & & & Z999999999999 \\
\hline
\end{tabular}

